\title{
ANL/NDM-17 \\ SAMPLE-SIZE EFFECTS IN \\ FAST-NEUTRON GAMMA-RAY \\ PRODUCTION MEASUREMENTS: \\ SOLID-CYLINDER SAMPLES
}

by

Donald I. Smith

September 1975

In January 1975, the research and development functions of the former U.S. Atomic Energy Commission were incorporated int.o those of the U.S. Fnergy Research and Development Adiministration. 
NUCLEAR DATA AND MEASUREMENTS SERIES

The Nuclear Data and Measurements Serles presents results of studies in the fleld of microscoplc nuclear data. The primary objective is the dissemination of information in the comprehensive form required for nuclear technology applications. This Series is devoted to: a) Measured microscoplc nuclear parameters, b) Experimental techniques and facilities employed in data measurements, c) The analysis, correlation and interpretation of nuclear data, and d) The evaluation of nuclear data. Contributions to this Serles are reviewed to assure technical competence and, unless otherwise stated, the contents can be formally referenced. Thls Serles does not supplant formal journal publication but it does provide the more extensive information required for technological applications (e.g., tabulated numerical data) in a timely manner. 
TABLE OF CONTENTS

Page

ABSTRACT. ...................... 3

1. INTRODUCTION. . . . . . . . . . . . . . 4

2. NUCLEAR DATA FOR COMPUTATIONS ........... 7

3. EFEECTS OF GEOMETRY AMD ABSORPTITON. . . . . . . . 8

3.1 Misthemat1cal Formal18m. ............ 9

3.2 Results of Numerical Studies. . . . . . . . 14

4. EFFTCTS OF NEUTRON MULTIPLE SCATTERING. . . . . . 20

4.1 Mathematical Formalism. . . . . . . . . . 20

4.2 Results of Numerical Studies. . . . . . . . 25

5. COMPARISON OF EXPERTMENTAL AND COMPUTED RESULTS

FOR NATURAL IRON SAMPLES. ............ 27

6. conclusions .................. 29

ACKNOWLEDGERENTS. . . . . . . . . . . . . . . 31

APPENDIX A: COHERENT PHOTON SCATTERING . . . . . . . . 32

APPENDIX B: LISTING OF CODE GAMSCT . . . . . . . . 34

REFEREICES. ...................... 45

TABlES. ...................... 46

FIGURES . . . . . . . . . . . . . . . . 51 
SAMPLE-SIZE EFFECTS IN

FAST-NEUTRON GAMMA-RAY

PRODUCTION MEASUREMENTS:

SOLID-CYLINDER SAMPLES ${ }^{*}$

by

Donald L. Smith

Argonne National Laboratory, Argonne, Illinois 60439, U.S.A.

\section{ABSTRACT}

The effects of geometry, absorption and multiple scattering in $(n, X Y)$ reaction measurements with solid-cylinder samples are Investigated. Both analytical and Monte-Carlo methods are employed in the analysis. Geometric effects are shown to be relatively insignificant except in definition of the scattering angles. However, absorption and multiple-scattering effects are quite important; accurate microscopic differential cross sections can be extracted from experimental data only after a careful determination of corrections for these processes. The results of measurements performed using several natural iron samples. (covering a wide range of sizes) confirm validity of the correction procedures described herein. It is concluded that these procedures are rellable whenever suffictently accurate neutron and photon cross section and angular distribution information is available for the analysis.

*This work was performed under the auspices of the U.S. Energy Research and Development Administration. 


\section{INTRODUCTION}

A recent report describes the facility which has been developed at Argonne National Laboratory's FiG for $(n, x \gamma)$ reaction studies $[1,2]$. The geometry is show in F1gu.1-6 of Ref. 1 and it $1 \mathrm{~s}$ recommended that the reader refer to this earlier report in conjunction with the present one. Experfence with this facility has indicated that the precision of raw data obtalned generally tmproves with Iticreased sample size. The relative importance of background decreases and the statistical accuracy of the significant data improves under these conditions. Furthermore, In measurements with relatively large samples, it. is posstble to exploit the advanteges of longer flight paths (Improved time-of-flight resolution) and massive detector shtelding. The penalty involved in measurenents with large samples is that corrections to the raw data for effects of absorption and multiple scattering can be quite large. Accurate determination of these corrections requires knowledge of neutron and photon cross sectlons and their angular distributions and use of complex corputational procedures. Clearly, a compromise ts necessary. The objective of this report 18 to present the results of a detalled study of sample-size effects which was conducted in the course of developing the data processing routines which are employed in the reduction of experimental data acquired with this facility.

The results of a literature survey were disappointing. There are relatively few readily avallable articles on the subject of sample corrections [3-13]. Most of these references deal with experiments in which neutrons (not gama rays) are detected. These articles provided guidance, but were not a basis for the present work.

The analysis presented in this report employs only a few simplifying assumptions and therefore adheres to a 
realistic representation of the physical problem.

The ${ }^{7} L I(p, n){ }^{7}$ Be reaction is usually used as a neutron source at this laboratory for measurements in the region of Interest for current $(n, X \gamma)$ studies $\left(E_{n} \lesssim 5 \mathrm{MeV}\right.$ ). Natural Iithium metal is evaporated onto a thin tantalum backing to form a target. The proton-beam spot on target is defined by slits and is essentially rectangular. The lithium films are relatively thin $\left(\Delta \mathrm{E}_{\mathrm{p}} \approx 0.1 \mathrm{Mev}\right)$. The analysis presented in this report assumes an infinitesimally thin square target; however, the routines actually used for data processing take cognizance of reallatic target thicknesses by superimposing contributions from several very thin layers. Target thickness is an important conaideration whenever the cross section varies rapidly with neutron energy or for proton energles near the resonance in the lithium source reaction at $\sim 2.3 \mathrm{MeV}$. The angular distribution of neutrons from the source reaction is taken into account. Neutrons from the ${ }^{7} \mathrm{LI}(\mathrm{p}, \mathrm{n}){ }^{7} \mathrm{Be}^{*}$ and ${ }^{7} \mathrm{LI}\left(\mathrm{p}, \mathrm{n}^{3} \mathrm{He}\right)^{4} \mathrm{He}$ reactions are considered in the analysis for proton energles above their production thresholds.

Gamia rays from $(n, X y)$ reactions are detected with a $\mathrm{Ge}(\mathrm{LI})$ detector and the ylelds of full-encrgy-peak events are recorded. Since the $\mathrm{Ge}(\mathrm{LI})$ detector has a diameter of $~$ $5 \mathrm{~cm}$ and $1 \mathrm{~s}$ placed $~ 100-150 \mathrm{em}$ from the sample, it is assumed that the only photons which are capable of producing full-energy pulses in the detector are those which either experience no interaction in the sample after production via $(n, X y)$ reactions or are coherently scattered in the semple. Therefore, the total photon cross section is asqumed for sample absorption calculations and a small correction for coherent scattering is applied when necessary (see Appendix A).

The scattering of neutrons in the sample: by elastic and Inelastic scattering through discrete levels is treated. 
The effects of more complicated reactlons auch as $(n ; 2 n)$, $(n ; n, p),(n ; n, p),(n ; n, \alpha)$, etc. are Insignificant for $E_{n}\lceil 5 \mathrm{MeV}$ so they are Ignored in the comutations. RInenatic effects are conoldered, and energy-dependent cross sections and angular distributions are employed. The scattering aample is assumed to be a uniform right-circular cylinder centered on the heam line with axis normal to the scattering plane defined by the bean Iine and the detector. Macroscopic crose sections are used in absorption calculations, and samples consieting of either uingle- or multiple-1sotope elements, compounde or mixtures can be treated.

Let

$$
\begin{aligned}
& Y_{\text {TOr }} \text { - total observed gama-ray yield for a } \\
& \text { particular geometry, } \\
& Y_{0}=\text { gama-ray yield produced by unacattered } \\
& \text { neutrons, } \\
& Y_{\ell}=\text { gama-ray yield produced by neutrons which } \\
& \text { have acattered " } l \text { " } t \text { imes in the sample be- } \\
& \text { fore Initlating ( } n, \mathbf{K} \gamma) \text { reactions, } \\
& k \text { = highest order of scattering considered, }
\end{aligned}
$$

then

$$
Y_{\text {TOT }} \lesssim Y_{0}+S_{l=1}^{k} Y_{\ell}=Y_{0}\left[1+\sum_{l=1}^{k}\left(Y_{\ell} / Y_{0}\right)\right]
$$

If

$$
\begin{aligned}
& a_{\ell}=\left(Y_{\ell} / Y_{0}\right), \\
& a_{\text {Tor }}=\sum_{\ell=1}^{k} a_{\ell},
\end{aligned}
$$

then

$$
Y_{\operatorname{TOT}} \lesssim Y_{0}\left(1+a_{\text {TOT }}\right)
$$

The symbol $S$ represents sumation to avold confusion with $\Sigma$ used for macroscopic cross sections elsewhere in this report. The quantity $\alpha_{\text {Tor }}$ is called the multiple- 
scattering parameter and $\alpha_{\ell}$ is the $\ell-t h$ component. For most samples,

$$
a_{\text {TOT }}<1 \text { and } a_{\ell+1} \ll a_{\ell},
$$

and the oums in Eqs. 1 and 3 converge rapldly. Acceptable accuracy is obtalned in practice for $k \leq 3$.

The evaluation of $\mathrm{Y}_{0}$ and $\alpha_{\text {TOT }}$ are treated separate1y. The quantity $Y_{0}$ is determined analytically while $\alpha_{\text {TOT }} 1 \mathrm{~s}$ deduced by Monte-Carlo methods.

The acquisition of nuclear data required for the computations is considered in Section 2; this is a problem which must be addressed before any sample-size correction factors can be computed. Section 3 of this report deals with evaluation of $Y_{0}$ and Its relationship to the $(n, X Y)$ reaction differential cross section which is sought from the meagurements. Section 4 treats the subject of multiple scattering and determination of $\alpha_{\text {TOT. }}$ In Section 5, the results of computations are compared with experimental data and a simplified computational procedure is explored.

\section{NUCLEAR DATA FOR COMPUTATIONS}

The methods for computation of sample correction factors described in this report are powerful in principle; however, the quality of the results obtained is oniy as good as the accuracy of the nuclear data utilized in the analysis. Thus, the experimenter must exercise judgement In selection of the sample size for an experiment. If the available cross section and angular distribution information is uncertain, it is necessary to use smaller samples and thereby sacrifice sensitivity and statisical accuracy in order to minimize the magnitude of the corrections which must be computed. Actually, the quality of avaliahle nuclear data is gradually imr,roving, and high- 
speed digital computers are accessible to most researchers. Therefore, it appears worthwhile to develop the sophist1cated computational tools required to determine realiatic corrections and explott the experimental advantages of using relatively large samples whenever possible.

The existence of pronounced resonante structure in nuclear data complicates many aspects of nuclear science and technology; the present topic 18 no exception. It has been found convenient to smooth all energy-dependent nuclear data used in correction calculations with resolution functions which approxfmate the experimental conditions. The smoothed excitation functions can usuaily be represented with sufficient accuracy by a relatively small number of parameters. F18. 1 demonstrates the concept. The use of smoothed cross sections for sample absorption and multiple-scattering calculations is an approximation, the validity of which must be investigated carefully prior to use in applications. One method is to compare the results of small- and large-sample measurements in reglons where strong resonances are present in the cross sections.

Neutron cross section and angular distribution information is obtained from the eveluated neutron data file, ENDF/B-IV [14]; photon cross sections are obtained from an evaluation by Storm and Israel [15].

\section{EFFECTS OF GEOMETRY AND ABSORPTION}

The dominant features of the observed gammo-ray yleld from $\left(n, X_{\gamma}\right)$ reactions in the sample are decermined by geometry and the absorption of neutron and gamma radiation. These features are predicted by the response of $\mathrm{Y}_{0}$ in Eq(4) to variation of the experfmental conditions. Multiple scattering, represented by $a_{\text {TOT }}$ in Eq. (4), ylelds a less significant correction to this behavior. This section describes the procedure used to compute $Y_{0}$ and presents the results of calculations designed to explore the sensitivity 
of $\mathrm{Y}_{0}$ to various parameters.

\subsection{Mathemat 1cal Formal 1sm}

The yleld for the entire sample ts computed by summing the contributions from varlous portions of the sample. The neutron source and the sample are represented as described below. Fig. 2. illustrates the geonetry.

Let

$d_{n}=d_{1 s t a n c e}$ from a particular neutron source point to a particular sample point,

$d_{\gamma}=$ distance from a particular sample point to the ganma-ray detector (assumed to be single point),

$\delta_{n}=d$ istance through the sample which the neutron must penetrate to reach the particular samp?.e point,

${ }_{\gamma}=$ distan:e through the sample which the gamma ray must penetrate to reach the gama-ray detector,

$R_{S}$ - radius of the sample,

H = height of the sample,

$D_{n}=$ distance from the center of the neutron source to the center of the sample (whIch is also the pivot for the gama-ray detector),

$D_{Y}=$ distance from the center of the sample to the gamma-ray detector,

$\theta_{n}$ - Incident-neutron angle relative to the beam line,

$\theta_{D E T}=$ angle of gamma-ray detector relative to the beam line,

$\theta_{n \gamma}=$ angle of emission of the gamma ray relative to the Incident neitrun,

$F_{\mathrm{n}}=$ absolute neutron-source strength of a uniform square source (neutrons/sr),

a = dimension of the square neutron source, 


$$
\begin{aligned}
& (d \sigma / d \Omega)_{\gamma}=\text { differential gamma-ray production } \\
& \text { cross section for the }(n, X \gamma) \text { re- } \\
& \text { action, } \\
& \left(x_{T}, y_{T}, z_{T}\right)=\text { coordinates for a point osi the neu- } \\
& \text { tron-source surface, } \\
& \left(x_{1}, y_{1}, z_{1}\right)=\text { coordinates for a point } s_{1} \text { in the } \\
& \text { sample, } \\
& \left(x_{D}, y_{D}, z_{D}\right)=\text { coordinates for the gamma-ray de- } \\
& \text { tector, } \\
& \mathrm{N}_{\mathrm{S}}=\text { number of atoms per unit volisme of } \\
& \text { the sample which can contribute to } \\
& (\mathrm{n}, \mathrm{X} \gamma) \text { reactions, } \\
& \Sigma_{\mathrm{nT}}=\text { neutron macroscopic total cross } \\
& \text { section for the sample material, } \\
& \Sigma_{\gamma \mathrm{T}}=\text { photon macroscopic total cross sec- } \\
& \text { tion for the sample material. }
\end{aligned}
$$

Two-body neutron-producing reactions are assumed in the present analysis. The neutron fluence $F_{n}$ is a function of the reaction parameters, incident energy, and emission angle. Kinematics governs the variation of neutron energy with angle. The cross sections $(d \sigma / d \Omega), \Sigma_{n T}$ and $\Sigma_{\gamma T}$ are energy-dependent; (do/d $)_{\gamma}$ also varies wtth angle $\theta_{n \gamma}$.

The grid systems for the neutron source and the sample are illustrated in Fig. 2. The sample grid system used yields more uniformly sized elements than a standard cylindrical-coordinate grid system. The parameters which define these grid systems are

$n_{H}=$ mesh for the sample height (the sample is divided into $n_{H}$ layers of height $\mathrm{H} / \mathrm{n}_{\mathrm{H}}$ along the $x$-axis),

$n_{R}$ - radial mesh (the sample is divided into a series of $n_{R}-1$ shells of thiskness $R_{S} / n_{R}$ plus a central cylinder with radius $\left.R_{S} / n_{R}\right)$,

$n_{\phi}=$ fundamental angular mesh (the central cylinder, $f=1$, is divided into $n_{\phi}$ wedges while 


$$
\begin{aligned}
\text { the } \left.j \text { th shell has } j n_{\phi} \text { segments, } j=2, \ldots, n_{R}\right) & \\
n_{T}= & \text { neutron-source mesh (the square source io } \\
& \text { divided into } n_{T}{ }^{2} \text { sections each with area } \\
& a^{2} / n_{T}^{2} \text { ). }
\end{aligned}
$$

The total number of elements in the sample is $\frac{1}{2} n_{H} n_{\phi} n_{R}\left(n_{R}+1\right)$.

The variation in volume of these elements depends only on the radial variable. Therefore

$$
v_{f}=\frac{\pi R_{S}^{2} H}{n_{R}^{2} n_{H} n_{\phi}}\left(\frac{2 j-1}{j}\right), j=1, \ldots, n_{R} \text {. }
$$

A constraint on the angular mesh $n_{\phi}$, required for the type of sample grid used, is $n_{\phi} \geq 2$.

The intercept of the beam line and neutron source plane is selected as the origin of coordinates. The coordinates of the center of each neutron-source element are given by $\left(x_{T \alpha}, y_{T \beta}, z_{T}\right)$ where

$$
\begin{aligned}
& x_{T \alpha}=\frac{a}{2 n_{T}}\left(2 \alpha-n_{T}-1\right), \alpha=1, \ldots, n_{T}, \\
& y_{T \beta}=\frac{a}{2 n_{T}}\left(2 \beta-n_{T}-1\right), \beta=1, \ldots, n_{T},
\end{aligned}
$$

and $z_{T}=0$ for all elements.

The coordinates of the gamma-ray detector are given by the formulas

$$
\begin{aligned}
& y_{D}=D_{\gamma} \sin \theta_{D E T}, \\
& z_{D}=D_{n}+D_{\gamma} \cos \theta_{D E T},
\end{aligned}
$$

and $x_{D}=0$.

The coordinates of the center of each sample element are given by the formulas

$$
\begin{aligned}
& x_{1 i}=\frac{H}{2 n_{H}}\left(21-n_{H}-1\right), i=1, \ldots, n_{H}, \\
& y_{1 j k}=r_{j} \sin \phi_{j k}, j=1, \ldots, n_{R} \text { and } k=1, \ldots, j n_{\phi},
\end{aligned}
$$




$$
\begin{aligned}
& z_{i j k}=D_{n}+r_{j} \cos \phi_{j k}, j=1, \ldots, n_{R} \text { and } \\
& k=1, \ldots, j n_{\phi} \text {, }
\end{aligned}
$$

and

$$
\begin{aligned}
& r_{j}=\frac{R_{S}}{2 n_{R}}(2,-1), j=1, \ldots, n_{R}, \\
& \phi_{j k}=\frac{\pi}{j n_{\phi}}(2 k-1), j=1, \ldots, n_{R} \text { and } k=1, \ldots, j n_{\phi}
\end{aligned}
$$

Analytic geosetry is applied in derivation of formulas for $\delta_{n}$ and $\delta_{\gamma}$. The expression for $\delta_{n}$ is

$$
\delta_{n}=d_{n}-s_{n},
$$

where

$$
\begin{aligned}
d_{n} & =\left[\left(x_{1}-x_{T}\right)^{2}+\left(y_{1}-y_{T}\right)^{2}+\left(z_{1}-z_{T}\right)^{2}\right]^{\frac{1}{2}}, \\
a_{n} & =\frac{\left[B_{n}\left(y_{0}-y_{T}\right)+C_{n}\left(z_{0}-z_{T}\right)\right]}{\left(B_{n}{ }^{2}+C_{n}{ }^{2}\right)} \\
& -\frac{\left(\left(B_{n}{ }^{2}+C_{n}{ }^{2}\right) R_{S}{ }^{2}-\left[C_{n}\left(y_{T}-y_{0}\right)-B_{n}\left(z_{T}-z_{0}\right)\right]^{2}\right\}^{\frac{1}{2}}}{\left(B_{n}{ }^{2}+C_{n}{ }^{2}\right)}
\end{aligned}
$$

$$
\begin{aligned}
& B_{n}=\left(y_{1}-y_{T}\right) / d_{n}, \\
& C_{n}=\left(z_{1}-z_{T}\right) / d_{n},
\end{aligned}
$$

and $\left(x_{0}, y_{0}, z_{0}\right)$ are the coordinates of the center of the sample $\left(x_{0}=y_{0}=0, z_{0}=\theta_{n}\right)$. The expression for $\delta_{\gamma}$ is

$$
\delta_{\gamma}=d_{\gamma}-s_{\gamma},
$$

where

$$
\begin{aligned}
d_{\gamma} & =\left[\left(x_{1}-x_{D}\right)^{2}+\left(y_{1}-y_{0}\right)^{2}+\left(z_{1}-z_{D}\right)\right]^{\frac{3}{2}}, \\
s_{\gamma} & =\frac{\left[B_{\gamma}\left(y_{0}-y_{D}\right)+C_{\gamma}\left(z_{0}-z_{D}\right)\right]}{\left(B_{\gamma}{ }^{2}+C_{\gamma}{ }^{2}\right)} \\
& -\frac{\left[\left(B_{\gamma}{ }^{2}+C_{\gamma}{ }^{2}\right) R_{S}{ }^{2}-\left[C_{\gamma}\left(y_{D}-y_{0}\right)-B_{\gamma}\left(z_{D}-z_{0}\right)\right]^{2}\right\}^{\frac{1}{2}}}{\left(B_{\gamma}{ }^{2}+C_{\gamma}{ }^{2}\right)}, \\
B_{\gamma} & =\left(y_{1}-y_{D}\right) / d_{\gamma}
\end{aligned}
$$


Let

$$
\begin{aligned}
& n_{n}=\text { neutron absorption factor, } \\
& n_{Y}=\text { gamma-ray absorption factor, }
\end{aligned}
$$

then

$$
\begin{aligned}
& \eta_{n}=\exp \left(-\Sigma_{n T}{ }^{\delta}{ }_{n}\right), \\
& \eta_{\gamma}=\exp \left(-\Sigma_{\gamma T}{ }^{\delta} \gamma\right) .
\end{aligned}
$$

If

$$
\begin{aligned}
\varepsilon_{\mathrm{DET}}= & \text { efficiency of the gamma-ray detector, } \\
& \text { defined as the ratio of detected (In the } \\
& \text { ful1-energy peak) to incident gamma rays, }
\end{aligned}
$$

then

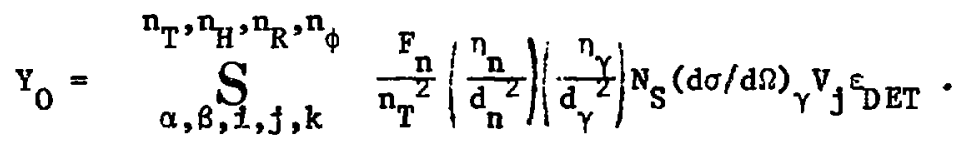

$Y_{0}$ is a function of $E_{n}$ and $\theta_{n \gamma}$. The energy $E_{n}$ lies in the range $\left(0, \mathrm{E}_{\mathrm{n}, \max }\right)$ while the scattering angle $\theta_{n \gamma}$ is in the range $(0, \pi)$. Therefore, it is possible to define resolution functions $\mathscr{E}\left(E_{n}\right)$ and $\mathscr{C}\left(\theta_{n \gamma}\right)$ such that

$$
\begin{aligned}
& \mathrm{Y}_{0}=\int_{0}^{\mathrm{E}} \mathrm{n, \operatorname {max }} \mathscr{E}\left(\mathrm{E}_{\mathrm{n}}\right) \mathrm{dE} \mathrm{E}_{\mathrm{n}}, \\
& \mathrm{Y}_{0}=\int_{0}^{\pi} \mathscr{A}\left(\theta_{n \gamma}\right) \mathrm{d} \theta_{n \gamma} .
\end{aligned}
$$

These resolution functions can be used to compute the average neutron energy $\left\langle E_{n}\right\rangle$ and the average scattering angle $<\theta_{n \gamma}>$ according to the formulas

$$
\begin{aligned}
& \left\langle E_{n}>=Y_{0}^{-1} \int_{0}^{E_{n}, \text { max }} E_{n} \mathscr{E}\left(E_{n}\right) d E_{n},\right. \\
& \left\langle\theta_{n \gamma}>=Y_{0}^{-1} \int_{0}^{\pi} \theta_{n \gamma} \mathscr{A}\left(\theta_{n \gamma}\right) d \theta_{n \gamma} .\right.
\end{aligned}
$$

The relationship between $Y_{0}$ and the differential cross section $(\mathrm{d} \sigma / \mathrm{d} \Omega)_{\gamma}$ is indicated in $\mathrm{Eq}$. (28). Let 
$<(d \sigma / d \Omega)_{\gamma}>=$ value of the differential cross section corresponding to neutron energy $\left\langle E_{n}\right\rangle$ and scattering angle $<\theta_{n \gamma}>$,

and define

$\left.\xi_{\gamma}=(\mathrm{d} \sigma / \mathrm{d} \Omega)_{\gamma} /<(\mathrm{d} \sigma / \mathrm{d} \Omega)_{\gamma}\right\rangle$,

then $\mathrm{Eq}$. (28) can be rewritten in the form

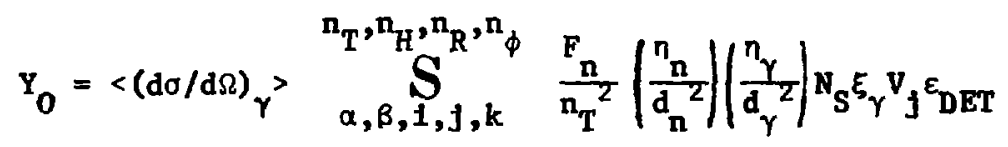

which explicitly relates the gamma-ray yleld to the differential cross section for a specific neutron energy and scattering angle. This formalism requires an approximate knowledge of $\xi_{\gamma}$ (the shape of the differential cross section function in terms of neutron energy and scattering angle). In practice, most of the contributions to $Y_{0}$ come from limited ranges of neutron energy and scattering angle. Therefore, one estimates the behavior of $\xi_{\gamma}$ for the reglons of Intereat and applies this est1mate in computations. Improved accuracy can be achieved by the process of 1teration. Experfence has shown no more than two passes are required for most applications.

\subsection{Results of Numerical Studies}

It is worthwhle to factor the gross solld-angle and sample-volume dependence from the expressions for $Y_{0}$. This can be achleved through defintition of the quantity $\bar{Y}_{0}$ as follows:

$$
Y_{0} \equiv\left(\pi R_{S}^{2} H D_{n}^{-2} D_{\gamma}^{-2}\right) \bar{Y}_{0} \text {. }
$$

In this section, sample geometry and absorption effects are investigated solely in terms of the behavior of $\overline{\mathrm{Y}}_{0}$. 
A Systems Engineering Laboratories Model 840 MP digftal computer was utilized in computation of $\bar{Y}_{0}$ for varfous experimental conditions. A nominal parameter set for these calculations appears in Table $I$. The vartation of $\bar{Y}_{0}$ in response to departures from the conditions represented by these parameters is investigated in the present section.

Selection of an appropriate set of mesh parameters $n_{T}, n_{H}, n_{R}$ and $n_{\phi}$ is an important consideration. Coarse meshes lengthen the computation time unnecessarily. The romputations were least sensitive to $n_{T}$ and most sensitive to $n_{R}$ as expected. The mesh parameters listed in Table I appear to be satisfactory for most practical applications.

The effects of radiation absorption were investigated by computing $\bar{Y}_{0}$ for four sets of parameters which differ from each other only in the assumed values for $\Sigma_{n t}$ and $\Sigma_{\gamma T}:$ i) neutron and gamma-ray absorption (Table I), ii) gamma-ray absorption only $\left(\Sigma_{n T}=0\right)$, 111$)$ neutron absorption only $\left(\Sigma_{\gamma T}=0\right)$, and $\left.1 v\right)$ no absorption $\left(\Sigma_{n T}=\Sigma_{\gamma T}=0\right)$. The effects of absorption are a reduction of gamma-ray yield and a distortion of the observed angular distribution. The relative gamma-ray yields at $\theta_{\Delta \mathrm{ET}}=90^{\circ}$ for these four cases are: 1) 0.34 , 11) 0.50 , iii) 0.68 , and $f v) 1.00$. The induced anisotropy for each situation is shown in Fig. 3. These distortions appear to be well represented by the expression

$$
\bar{Y}_{0}\left(\theta_{D E T}\right) \approx \bar{Y}_{0}\left(90^{\circ}\right)\left(1-\Delta_{0} \cos \theta_{D E T}\right)
$$

with $\Delta_{0}$ assuming the following positive values for the four cases considered: 1) 0.172 , i1) 0.0658 , 1ii) 0.0056 , 
and Iv) 0.0021. Geometric effects and neutron attenuatIon alone produce very little distortion; however, gamaray absorption (particularly in combination with neutron absorption) skews the observed angular distribution about $\theta_{\mathrm{DET}}=90^{\circ}$ so that the back-angle yleld exceeds the forward-angle yleld.

The relative contributions to $\bar{Y}_{0}$ for $\theta_{D E T}=90^{\circ}$ from the midplane sample elenents are presented for each of the four cases considered as follows: 1) FIg. 4, 11) FIg. 5, 111) Fig. 6, and IV) Fig. 7. In confunction with the results presented in Figs. 4-7, it is worthwhile to consider the ratios of ylelds from larger segments of the sample. Define the "back" of the sample as that half of the cylinder which 18 farthest from the neutron source, and the "front" of the sample as the opposite half. Simllarly, label as "far" the sample half farthest from the gamma-ray detector. The opposite half is labelled as "near". Computed "front"-to-"back" and "near"-to-"far" rat1og are listed in Table II.

The parameter $D_{n}$ was varled over the range $5-50 \mathrm{~cm}$ with other parameters fixed at the values given in Table I. The value of $\bar{Y}_{0}$ for $\theta_{\mathrm{DET}}=90^{\circ}$ increased by only $3.3 \%$ as $D_{n}$ Increased from 5 to $50 \mathrm{~cm}$. Th1s would seem to Imply that a parallel neutron beam approximation is warranted. However, variation in the distortion of the angular distribution was more pronounced as $\Delta_{0}$ decreased from 0.268 for $D_{n}=5 \mathrm{~cm}$ to 0.121 for $D_{n}=50 \mathrm{~cm}$. For small values of distance $D_{n}$, the sample subtends a sizeable solld angle so that the average scattering angle becomes quite sensitive to $D_{n}$. Therefore, use of the paralle1 neutron beam approximation is not recomended.

The parameter $D_{\gamma}$ was varled over the range $30-200 \mathrm{~cm}$ with other parameters fixed at the values given in Table 1. The value of $\bar{Y}_{0}$ for $\theta_{D E T}=90^{\circ}$ decreased by only 1.27 
as $\mathrm{D}_{\gamma}$ increased from 30 to $200 \mathrm{~cm}$, and the distortion parameter $\Delta_{0}$ decreased from 0.190 to 0.168 . A parallel gamma ray approximation could be justified for these calculations.

Varlation of the sample height $H$ produces very little effect on $\bar{Y}_{n}$; however, the gamma-ray yleld and distortion of the angular distribution depend critically upon the sample radius $R_{S}$. Computations were made for $R_{S}=0.635$, $0.95,1.27,1.59,1.905$ and $2.54 \mathrm{~cm}$ with the other parameters fixed at the values listed in Table $I$. The results of these calculations appear in Table III. The near constancy of $R_{S} \bar{Y}_{0}$ for large values of $R_{S}$ implies that, in this domain, the total gamma-ray yleld from the sample Increases more or less Inearly with sample radius rather than as the square of the radius. The difference is due to absorption. Clearly, the total gamma ray yield from the sample also increases linearly with sample helght. A set of calculations was made assuming no neutron or gama-ray absorption and using values of $H=2 R_{S}$ ("square" samples). As $R_{S}$ increases from $0.635 \mathrm{~cm}$ to $2.54 \mathrm{~cm}, \overline{\mathrm{Y}}_{\mathrm{O}}$ decreases by 1.7\%. This result Indicates that the yleld per unit volume depends only slightly on the size of the sample in the absence of absorption.

The most significant geometric effect is the 10ss of angular resolution which results from the use of large samples. The maximum geometric angular range for $\theta_{\mathrm{nr}}$ assoclated with the conditions of Table I is $\sim 19^{\circ}$. The contribution to this spread from the neutrons $1 \mathrm{~s} \sim 17^{\circ}$ while that from the gamma rays $18 \sim 2^{\circ}$. The resolution functions $\left(\theta_{\mathrm{n} \gamma}\right)$, as defined by $\mathrm{Eq}$. (30), were determined for several values of $\theta_{\mathrm{DET}}$ using Table I parameters. The results are presented In Fig. 8. Values of $\left\langle\theta_{n \gamma}\right\rangle$, computed with these resolution functions, differ olgnificantly from the corresponding detector angles $\theta_{\mathrm{DET}}$ when $\theta_{\mathrm{DET}}$ approachea 
$0^{\circ}$ or $180^{\circ}$. Th1s result 111ugtrates the we11-known fact that relatively small samples are required for the measurement of differential cross sectlons near $0^{\circ}$ or $180^{\circ}$.

Gamma-ray angular distributions for $(n, X Y)$ reactions are symetric about $\theta_{n \gamma}=90^{\circ}$. Computations were made using varlous assumed gama-ray differential cross section functions $(d \sigma / d \Omega)_{\gamma}$. These calculations indicate that, for positive values of $\Delta_{0}$, the formula

$$
\bar{Y}_{0} \tilde{\sim} \text { (Constant) }\left(1-\Delta_{0} \cos \theta_{D E T}\right)<(d \sigma / d \Omega)_{Y}>
$$

Is valid to a considerable degree of accuracy. Furthermore, the distortion parameter $\Delta_{0}$ and the average scattering angle $<\theta_{n \gamma}>$ are very insensitive to the shape of the differential

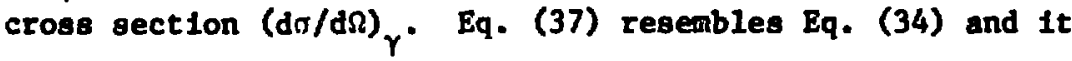
Is concluded that the complicated sum given in Bq. (34) has a simple angular dependence. This particular result will be designated the "factorization rule" since it provides a preacription for relating the observed gama-ray yield to the shape of the differential cross section. Fig. 9 demonstrates the factorfization rule. This rule applies reasonably well for most realistic applications even when wultiple scattering is taken into consideration (Section 4,2). Application of the factorization rule leads to a significant labor reduction in processing angular distribution data.

Realistically, the neutron field produced by proton bombardment of natural lithiu is a mixture of firat- and second-group neutrons plus some breakup nautrons at higher bombarding energles (Section 1). The energles and angular dfstributions of these components differ and this w11 influence the overall gma-ray and monitor yielde obaerved. of concern, however, is the effect of superposition of contributione on the applicability of the factorization rule. To Imvestigate this point, computations were made for ovveral incident energles aouning realfotic ifthiu firat= 
and second-group neutrons plus some breakup neutrons at h1gher bombarding energies (Section 1). The energles and angular distributions of these components differ and this w111 influence the overall gamma-ray and monttor ylelds observed. Of concern, however, is the effect of superposition of contributions on the applicability of the factorization rule. To investigate this point, computations were made for several incident energies assuming realistic lithium first- and second-group neutron sources as well as the hypothetical 1sotroplc source Identified in Table I. These calculations show that the distortion parameter $\Delta$ is relatively insensitive to the shape of the neutron-source reaction angular distribution. The parameter $\Delta$ varies with neutron energy since it depends on the total cross section. However, since $\Delta \ll 1$ for typical conditions, the energy dependence of $\Delta$ does not affect the angular distributions severely. For example, $\Delta$ is found to vary by $\sim 30 \%$ over the range $E_{n}=0.9-2 \mathrm{MeV}$ for the sample described in Table I; however, the ratio $\bar{Y}_{0}\left(0^{\circ}\right) / \bar{Y}_{0}\left(90^{\circ}\right)$ varies by only $\sim 3 \%$ over this range. Therefore, it is often possible to apply the factorfzation rule for multigroup neutron sources. The farmulas suggested by the results of numerical analyals are

$$
\begin{aligned}
& \bar{Y}_{0} \text { (multigroup) } \approx \text { (Constant) }\left(1-\left\langle\Delta>\cos \theta_{\text {DET }}\right) .\right. \\
& S_{m} G_{m}\left\langle(d \sigma / d \Omega\rangle_{m}\right. \text {. } \\
& \langle\Delta\rangle=\left(S_{m} G_{m} \Delta_{m} / S_{m} G_{m}\right)
\end{aligned}
$$

The parameters $G_{m}$ depend upon the group intenaitiea and aample absorption properties for neutrons in these groupa. The factorization rule is not a rigorous product of the formalisw, but is an emperical concept which has been 
distilled from the results of numerical calculations. Caution should be exerclsed when using this rule in processing data, particularly for measurements involving multigroup neutron sources.

\section{EFFECTS OF NEUTRON MUTIPLE SCATTERING}

The obvious result of multiple scattering is the enhancement of the observed yleld relative to that predicted by the computations of the previous section. The objectives of the present section are to describe the method used for the evaluation of the multiple scattering parameter $\alpha_{\text {TOT }}$ and to investigate the dependence of multiple scattering on various experimental factors.

\subsection{Mathemat1cal Formalism}

The approach taken in this work is to calculate values of $Y_{\ell}$ for $\ell=0,1, \ldots, k$ (see Section 1 ) by statistical methods and then compute the partial multiple-scattering parameters $\alpha_{\ell}$ by means of Eq. (2). The total multiplescattering parameter $\alpha_{\text {TOT }}$ is given by Eq. (3). There are several ways to formulate Monte-Carlo problems [13]. The present approach generally resembles that which is employed in multi-dimensional Monte-Carlo integration. The fundamental assumption of Monte-Carlo integration is that

$$
\int_{v} d \vec{q} f(\vec{q}) \approx \frac{v}{N_{h 1 s t}} S_{1=1}^{N h 1 s t} f\left(\vec{q}_{1}\right)
$$

for a suffictently large number of histories $\mathrm{N}_{\mathrm{hist}}$, where $\vec{q}_{1}$ is selected at random from a region of v-dimensional Cartesian space defined by

$$
\begin{aligned}
\vec{q} & =\left(q_{1}, q_{2}, \ldots, q_{v}\right) \\
d \vec{q} & =\left(d q_{1} d q_{2} \ldots . d q_{v}\right) \\
v & =\left(q_{1, \max }-q_{1, \min }\right)\left(q_{2, \max }-q_{2, \min }\right) \ldots\left(q_{v, \max }-q_{v, \min }\right)
\end{aligned}
$$


The region of space defined by the volume $V$ is a $v$-dimensional rectangle and is selected so that the true region of Interest lies entirely within V. The Monte-Carlo process consists of selecting points $\vec{q}_{1}$ at random in the larger region. If $\vec{q}_{1}$ falls outside the true region of interest, then $f\left(\vec{q}_{1}\right)=0$ (a "miss"). This approach does not lead to optimum efficlency, however such wastefulness is usually tolerable with high-speed digital computers and avolds many computational complexities.

Some of the variables used in this analysis are defined in Sections 1 and 3; others are defined at appropriate points in the present section.

First, computation of $\mathrm{Y}_{0}$ by Monte-Carlo methods is considered (see Fig, 10). The origin of coordinates is the neutron source (assumed here to be a point). The beam line is the z-axis, the sample axis is normal to the $y-z$ plane as in Section 3. The center of the sample is at the coordinates $\left(0,0, D_{n}\right)$. The gama-ray detector is a point in the $y-z$ plane located a d stance $D_{\gamma}$ from the center of the sample. The first-scattering point $S_{1}$ in the sample is Identifled by the vector $\vec{x}_{1}$ with coordinates $\left(x_{1}, y_{1}, z_{1}\right)$. A related spherical coordinate system can be defined by the equations

$$
\begin{aligned}
& x_{1}=r_{1} \sin \theta_{1} \cos \phi_{1}, \\
& y_{1}=r_{1} \sin \theta_{1} \sin \phi_{1}, \\
& z_{1}=r_{1} \cos \theta_{1} .
\end{aligned}
$$

The sample 1s located entirely within a region of space defined by the following expressions

$$
\begin{aligned}
& r_{I_{\text {min }}} \leq \mathrm{r}_{1} \leq \mathrm{r}_{1, \max ,} \\
& r_{1, \min }=\mathrm{D}_{\mathrm{n}}-\mathrm{R}_{\mathrm{S}}, \\
& r_{1, \max }=\left[\left(D_{n}+R_{S}\right)^{2}+\mathrm{H}^{2}+\mathrm{R}_{\mathrm{S}}^{2}\right]^{\frac{1}{2}},
\end{aligned}
$$




$$
\begin{aligned}
& 0<\phi_{1}<2 \pi, \\
& 0 \leq \theta_{1} \leq \theta_{1, \max }, \\
& \theta_{1, \max }=\tan ^{-1}\left[\left(\frac{1}{4} \mathrm{H}^{2}+\mathrm{R}_{\mathrm{s}}^{2}\right)^{\frac{1}{2}} /\left(\mathrm{o}_{\mathrm{n}}-\mathrm{R}_{\mathrm{S}}\right)\right] .
\end{aligned}
$$

The energy and angular dependence of all physical parameters is taken into consideration as well as kinematic effects. The gamma-ray yleld from $(n, X Y)$ reactions inftiated by unscattered neutrons is glven by

$$
Y_{0} \approx \frac{V_{1}}{N_{\text {hist }}} S_{1=1}^{N_{h 1 s t}} \Gamma_{01}
$$

with

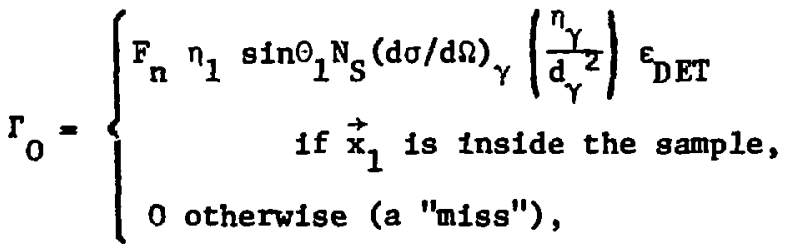

$$
\begin{aligned}
& n_{1}=\exp \left(-\delta_{n} \Sigma_{n T}\right) \text {, } \\
& v_{1}=2 \pi\left(r_{1, \max }-r_{1, \min }\right) \theta_{1, \max } .
\end{aligned}
$$

For $\vec{x}_{1}$ to 1 le inside the sample, it is required that

$$
\begin{aligned}
& -\mathrm{H} / 2<\mathrm{x}_{1}<\mathrm{H} / 2, \\
& {\left[\mathrm{y}_{1}^{2}+\left(\mathrm{z}_{1}-\mathrm{D}_{\mathrm{n}}\right)^{2}\right]^{\frac{3}{2}}<\mathrm{R}_{\mathrm{S}} .}
\end{aligned}
$$

Although determination of $\mathrm{Y}_{0}$ by Monte-Carlo integration is technically simpler than the approach described in Section 3, it is slower since quite a few historles are required for convergence. Furthermore, it is not possible to derive the midplane-yleld profile information presented in Figs. 4-7 from a simple Monte-Carlo treatment. However, for $\ell-1$ it is impractical to determine $Y_{\ell}$ by any method other than Monte-Carlo analysis. 
Next, consider computation of $\mathrm{Y}_{1}$ (see FIg. 10). The scattering preceding the $\left(n, X_{Y}\right)$ event can be elther elastic or inelastic. The possibility for more than one neutron channel adds an additional complication to the computations. Some neutrons which scatter in the vicinity of point $S_{1}$ propagate toward point $S_{2}$ defined by the vector $\vec{x}_{2}$. Assume that there are $N_{1}$ distinct scattering processes applicable to the first scattering point $S_{1}$. The $j-t h$ process is defined by the parameters $A_{1 j}, Q_{1 j}$ and $(d \Sigma / d \Omega)_{1 j}$ where

$$
\begin{aligned}
& A_{1 f}=\text { mass of the target nucleus, } \\
& Q_{1 J}=\text { reaction } Q \text {-value, } \\
& (d \Sigma / d \Omega)_{1 J}=\text { macroscopic differential neutron- } \\
& \text { scattering cross section. }
\end{aligned}
$$

For simplicity, the inelastic scattering processes are assumed to be isotropic since they are nearly so in reality. Let $\psi_{1}$ be the total macroscopic scattering cross section defined by the equation

$$
\psi_{1}=S_{j=1}^{N_{1}}(d \Sigma / d \Omega)_{1 j},
$$

then the relative probability $\mathrm{P}_{1 j}$ of each process is given by the equation

$$
P_{1 j}=(d \Sigma / d \Omega)_{1 j} / \psi_{1} .
$$

Since

$$
\int_{j=1}^{N_{1}} P_{1 j}=1,
$$

the unit interval can be divided by a set of $\mathrm{N}_{1}$ points $\left\{\rho_{1 j}\right\}$ defined by the equation

$$
\rho_{1 j}=\int_{\ell=1}^{j} \mathrm{p}_{1 \ell} \text {. }
$$


A random number $R$ is selected for each history. The neutron is then assumed to propagate from point $S_{1}$ to point $s_{2}$ by means of the $f$-th scattering process if

$$
\rho_{1, j-1}<R \leq \rho_{1 j} \text {. }
$$

Although the particular scattering process is selected by random sampling in the space of open channels, the macroscopic dif: erential scattering cross section used In the computation is $\psi_{1}$.

A new spherical coordinate system with origin at $S_{1}$ is defined. The cartesian coordinates (origin at the neutron source) and spherical coordinates in the new system for point $S_{2}$ are related by the equations

$$
\begin{aligned}
& x_{2}=x_{1}+r_{2} \sin \theta_{2} \cos \phi_{2}, \\
& y_{2}=y_{1}+r_{2} \sin \theta_{2} \sin \phi_{2}, \\
& z_{2}=z_{1}+r_{2} \cos \theta_{2} .
\end{aligned}
$$

The region of space defined by the expressions

$$
\begin{aligned}
& 0 \leq \theta_{2} \leq \pi, \\
& 0 \leq \phi_{2} \leq 2 \pi, \\
& 0 \leq r_{2} \leq r_{2, \max }, \\
& r_{2, \text { max }}=\left(H^{2}+8 R_{S}^{2}\right)^{\frac{3}{2}},
\end{aligned}
$$

encompasses the entire sample. Then,

$$
Y_{1} \approx \frac{v_{1} v_{2}}{N_{h 1 s t}} S_{1=1}^{N_{h i s t}} \Gamma_{11}
$$

with

$$
\begin{aligned}
& \int F_{n} n_{1} \sin \theta_{1} \psi_{1} n_{2} \sin \theta_{2} \text {. }
\end{aligned}
$$

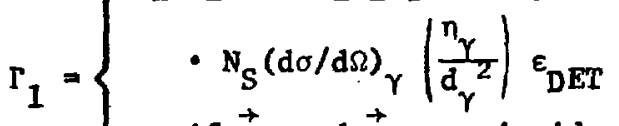

$$
\begin{aligned}
& \text { if } \vec{x}_{1} \text { and } \vec{x}_{2} \text { are inside the sample, } \\
& 0 \text { otherwise (a "miss"), } \\
& n_{2}=\exp \left(-r_{2} \Sigma_{n T}\right) \text {, } \\
& v_{2}=2 \pi^{2} r_{2, \max }
\end{aligned}
$$


For $\vec{x}_{2}$ to lie inside the cylinder, it is required that

$$
\begin{aligned}
& -\mathrm{H} / 2<\mathrm{x}_{2}<\mathrm{H} / 2, \\
& {\left[\mathrm{y}_{2}{ }^{2}+\left(\mathrm{z}_{2}-\mathrm{D}_{\mathrm{n}}\right)^{2}\right]^{\frac{1}{2}}<\mathrm{R}_{\mathrm{S}} .}
\end{aligned}
$$

Generalization to arbitrary orders of multiple scattering is straightforwaxd. The expression for $\mathrm{Y}_{\mathrm{k}}$ is$$
Y_{k} \approx \frac{V_{1} V_{2} \ldots V_{k+1}}{N_{\text {hlst }}} S_{i=1}^{N_{h i s t}} \Gamma_{k 1},
$$

with

$$
r_{k}=\left\{\begin{array}{c}
F_{n}\left(\prod_{l=1}^{k} n_{l} \sin \theta_{l} \psi_{l}\right) n_{k+1} \sin \theta_{k+1} \\
\cdot N_{s}(d \sigma / d \Omega) \\
\gamma\left(\frac{\eta_{\gamma}}{d_{\gamma^{2}}}\right) \varepsilon_{D E T} \\
\text { if } \vec{x}_{1}, \ldots, \vec{x}_{k+1} \text { are inside the sample, } \\
0 \text { otherwise (a"miss"). }
\end{array}\right.
$$

The parameters required for computation of all the higherorder scattering contributions resemble those described for computation of $\mathrm{Y}_{1}$.

Values of $\Gamma_{01}, \ldots, \Gamma_{k i}$ are computed for every history $\left(i=1, \ldots, \mathrm{N}_{\mathrm{h} \text { st }}\right)$. Whenever a particular $\Gamma_{\ell 1}$ $=0$ (a "miss"), the higher-order expressions $\Gamma_{\ell+1, i}$, ..., $\Gamma_{k i}$ are automatically equal to zero too. Thus, the efficiency for computation of $\mathrm{Y}_{k}$ declines with increased scattering order $k$. However,

$$
\mathrm{Y}_{0} \gg \mathrm{Y}_{1} \gg \ldots>\mathrm{Y}_{\mathrm{k}} \text {, }
$$

so it is unnecessary to determine the high-order contributions to $\mathrm{Y}_{\mathrm{TOT}}$ (Eq. 1) as accurately as the low-order contributions.

\subsection{Results of Numerical Studies}

Multiple-scattering calculations were performed with the SEL $840 \mathrm{MP}$ computer using a code named GAMSCT. This 
code has been written In FORTRAN IV and a listing of the orders is given in Appendix $B$.

A nominal set of parameters, which provided a starting point for numerical studies of multiple scattering, is given in Table IV. Experience indicates that for $k=3$, satisfactory accuracy in computation of $\alpha_{\text {TOT }}$ is achieved for $N_{\text {hist }} \approx 100,000$. This value was selected for all calculations. Typical efficiencies ("hit" percentages) of the Monte-Carlo trials are as follows: $Y_{0}(54.9 \%)$, $\mathrm{Y}_{1}(14.2 \%), \mathrm{Y}_{2}(3.7 \%)$ and $\mathrm{Y}_{3}(0.8 \%)$. Relative values of $\mathrm{Y}_{0}$, $\mathrm{Y}_{1}, \mathrm{Y}_{2}$ and $\mathrm{Y}_{3}$ for various $Q_{\mathrm{DET}}$ are plotted in Fig. 11. It is seen that the ratio $Y_{\ell+1} / Y_{\ell}$ is more or less independent of $\ell$, and furthermore for all $\ell$,

$$
\begin{gathered}
Y_{\ell}\left(\theta_{D E T}\right) \approx Y_{\ell}\left(90^{\circ}\right)\left(1-\Delta_{\ell} \cos \theta_{D E T}\right), \\
\Delta_{0}>\Delta_{1}>\Delta_{2}>\Delta_{3} \approx 0 .
\end{gathered}
$$

Intuitively, one expects the effects of geometric anisotropy to be washed out by multiple scattering. Eq. (79) supports this contention. Eq. (78) indicates that the factorization rule applies for an assumed isotropic differential cross section $(d a / d \Omega)_{\gamma}$. Actually it also applies reasonably well for most realistic differential cross section functions. However, the factorization rule does fail in extreme cases where $(d \sigma / d \Omega)_{\gamma}$ approaches zero for $\theta_{n \gamma}=0^{\circ}$ or $180^{\circ}$. Under these conditions, the observed yield for $\theta_{D E T}$ near $0^{\circ}$ or $180^{\circ}$ is dominated multiple scattering in a fashion which cannot be explained by a simple rule.

The effect of sample size was tested by varying $R_{S}$ and $H\left(H=2 R_{S}\right)$ with respect to the values in Table IV. The results are presented in Fig. 12. The contributions from second- and higher-order scattering are negligible for small samples. Variation of $D_{n}$ and $D_{\gamma}$ over realistic ranges produced very little effect on the computed multiple-scattering parameters. 
Computations performed with vartous assumed realist1c neutron-source reactions indicate that the multiplescattering correction parameters are relatively insensitive to the propertles of the neutron source. Therefore, it is reasonable to compute $\alpha_{\text {TOT }}$ for various energles $\mathrm{E}_{\mathrm{n}}$ and angles $\theta_{D E T}$ assuming an lsotroptc, monoenerget ic neutron source.

The multiple-s_alt,ring parameters are relatively Insensitive to $\Sigma_{n T}$ and $\Sigma_{\gamma T}$. However, they depend critically on the magnitudes of the scattering cross sections. The relationship

$$
\alpha_{\ell} \approx \text { (Constant) } \Sigma_{E L}^{\ell}
$$

gives a rough indication of this dependence for the simple case of energy-Independent elastic scattering. The multiple scattering parameters are considerably less sensitive to the shape of the neutron scattering angular distributions.

\section{COMPARISON OF EXPERIMENTAL AND COMPUTED RESULTS FOR \\ NATURAL IRON SAMPLES}

Measurements were performed with seven natural iron samples to test the validity of the methods described in this report. The sizes of the samples investigated were $R_{S}=0.635,0.953,1.27,1.59,1.91,2.22$ and $2.54 \mathrm{~cm}$ $\left(H=2 R_{S}\right)$. Realistic energy-averaged cross sections were utilized in the computations (Section 2 and Refs. 14 and 15). The facility described in Ref. 1 was utilized for the irradiations. A $0.1-\mathrm{MeV}$-thick natural lithium target was bombarded with $3.68-\mathrm{MeV}$ protons. Approximately $90 \%$ of the neutrons originated from the ${ }^{7} \mathrm{Li}(\mathrm{p}, \mathrm{n}){ }^{7} \mathrm{Be}$ reaction $\left(E_{n} \approx 2 \mathrm{MeV}\right.$ ) and $10 \%$ came from the ${ }^{7} \mathrm{Li}(\mathrm{p}, \mathrm{n}){ }^{7} \mathrm{Be}^{*}$ reaction $\left(E_{n} \approx 1.535 \mathrm{MeV}\right)$; the proton energy was slightly 
below threshold for the ${ }^{7} \mathrm{LI}\left(\mathrm{p}, \mathrm{n}^{3} \mathrm{He}\right)^{4} \mathrm{He}$ breakup react Ion. The Ge(L1) detector was sltuated at $0_{\text {DET }}=90^{\circ}$. The relative neutron fluence was monitored by time-of-filght techniques uaing a plastic scintillator.

The full-energy peak ylelds for the 0.846-MeV IIne from the ${ }^{56}$ Fe $\left(n, n^{2} \gamma\right){ }^{56}$ Fe reaction were divided by the masaes of the correaponding amples (proportianal to the volume) to deteraine quantities proportional to the yield per atom. All measurements were performed in 1dentical geometry, so the ylelda per atom deduced are proportional to $\bar{Y}_{0}\left(1+\alpha_{\text {ToT }}\right)$ as defined in Sectiona $1-4$.

Measureants for sapples with $R_{S}<0.635$ en were not practical because of background problens; however, computations were performed for a wide range of suple sizes including $R_{S}$ near zero. In the 1 intt of very anall simples, geometry, absorption and multiple-scettering effects vanish. The experimental and computed values were normalized so that the yield per atcm approaches unity for very small samples.

Four sets of computations were performed. The assumptions made in these calculations are as follows: 1) no absorption, geometric corrections only, 11) absorption of neutrons and gamma-rays with the neutron total cross section used for absorption calculations and multiple scattering neglected, 111) identical to (11) except that the total non-elastic cross section is used for the neutron absorption calculations, and iv) Identical to (ii) except multiple scattering is cotisidered (most reallstic approach). The resulte of these calculations are compared with the experimental data In Fig. 13. The calculations labelled (111) and (1v) both agree well with the experimental results; the agreenent of set (Iv) values $1 \mathrm{~s}$ superior as anticipated. The agreenent for such a wide range of sample sizes is very encouraging 
(the diameter of the largest anple considered is equivalent to 1.4 mean free path lengtha for nuvizrons and 2.5 mean tree path lengths for 0.846 -Hey photons). The asaumptions mude for the set (111) calculatLons vere aussested by Day (3). The Day approxtmation is uldely used by researchers in thz analysis of ( $\left.n_{3} X_{Y}\right)$ data. It is appealins because it elininates the nacesalty for performing auteiple-scatering calculations. The resulte show in FIs. 13 correspond to $\theta_{\text {Dat }}=90^{\circ}$. Computations vere performed to compare the predictsons of the Day approximation with those from the more realietic treatment at other ankles. The results of this analysis show that these two approaches yield result: which agree within $\approx 3 \%$ for $Q_{3 \mathrm{FT}}=90^{\circ}-150^{\circ}$; however, che agreenent for Ger $* 30^{\circ}-90^{\circ}$ is only vithin ${ }^{\circ} 7 \%$ (for an iron semple with $R_{S}=1.9 \mathrm{~cm}$ ). Thts surkests that for careful work. where accuractes of betcer than $10 \mathrm{H}$ are cought, it is advisable to employ a realistic treatent which includea aultple-scattering analyats. In applications where such accuracy is not sought, or is unfeasible, the Day approxtaction appears to be varranted since it anves considerable labor.

\section{6. concidustons}

The formallon described in this report provides a weans for determining differential cross section data for $(n, x y)$ reactions from measurements made using relatively large cylindrical saples provided that accurate absorption and scattering cross section data is avallable.

Geometric effects reduce angular resolution and nake it difficult to measure differential cross sections near $0^{\circ}$ or $180^{\circ}$; otherwlse, they have a relatively minor influence on the geasurements.

The absorption of radiation reduces the overa11 yield and distorts angular distributions. Under most conditions, this distortion ussunes the form 1- $\Delta \cos \theta_{\mathrm{DET}}$ 
$(\Delta>0)$; the shape of the differential crosa section can be deduced from the experimental data by factoring out this alaple angular dependence. Factorization 18 posstble, even in the presence of multiple scattering, for most realiatic situations and this saves considerable labor in proceseing data.

The Day apprcximation [3] permite one to avold making decalled multiple scattering calculations, and appeare to be an acceptable approach when accuracles of no better than $\sim 10 \%$ are acceptable. 


\section{ACKNOWLEDGEMENTS}

The author is indebted to J. W. Meadows and P. T. Guenther for valuable suggestions offered during the course of this work. 
APPENDIX $\wedge$

COMERENT PHOTON SCATTERIM

Photons which scatter coherently in the sample are Indistinguishable from those which suffer no interact lon. The coherent scatering cross sections depend upoz photon energy $E_{\gamma}$ and atomlc number 2 . They decrease Engldly with $E_{\gamma}$. For this reason, the coherent scattering corrections are relat 1yo:y anall for most materials of Interest when $E_{\gamma}$ exceeds a few hundred kflovolta.

In order to estinate the correction, a model which assumes a wel1-defined, distributed gama-ray source intensity In a solid cylinder is employed. The unscattered and coherently-scattered photon yleld at a distant detector is computed as described below.

If $\Sigma_{\gamma, C O H}$ is the integrated macroscoplc coherent scattering cross section, then the macroscople differentisl scattering cross sectior is given by

$$
(d \Sigma / d \Omega)_{\gamma, \mathrm{COH}}=\frac{3 \Sigma_{\gamma, \mathrm{COH}}}{16 \pi}\left(1+\cos ^{2} \theta_{\gamma}\right) \text {. }
$$

Assume that the cylinder is divided into a large number of discrete elements. Let

$$
\begin{aligned}
\vec{x}_{1}= & \text { coordinates of the center of the } 1 \text {-th element } \\
\Delta V_{1}= & \text { isotropic gamma-ray source strength density } \\
& \text { for the } 1 \text { th component (gamma rays/sr } / \mathrm{cm}^{3} \text { ), } \\
\vec{x}_{\Delta}= & \text { coordinates of the detector. } \\
\delta_{1}= & \text { distance through sample material which the } \\
& \text { photon must penetrate to reach the detector } \\
& \text { if it originates at point } \vec{x}_{1} \text { (See Section } 3 \text { ), } \\
Y_{U}= & \text { yield at the detector due to unscattered photons } \\
Y_{S}= & \text { yield due to photons which have scattered once } \\
& \text { coherently in the sample. }
\end{aligned}
$$




$$
\begin{aligned}
& y_{U} \approx S \frac{s_{1} \Delta V_{1} \exp \left(-\Sigma_{\gamma T} t_{1}\right)}{\left|\vec{x}_{01}-\vec{x}_{D}\right|} \epsilon_{D F T}
\end{aligned}
$$

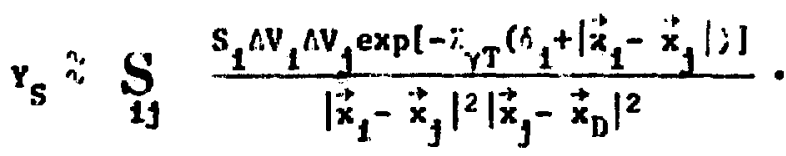

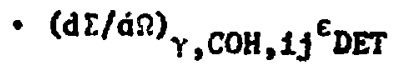

The problem has been formulated in cylindrical coordinates and a code is avallable for operation on the SEL 840 MP digital computer. A number of calcuiations were performed nssuning a constant value for $S_{1}$ throughout the sample. Samples with $R_{S}=1.9 \mathrm{~cm}$ and $\mathrm{H}=3.8 \mathrm{~cm}$, fabricated from $L 1, A l, T i, F e, Z n$ and $M o$, were cons1dered. The detector was assumed to be $130 \mathrm{~cm}$ from the sample. The ratio $Y_{v} /\left(Y_{U}+Y_{S}\right)$ was computed for $E_{V}=$ $0.1,0.3,0.5,0.8,1.0,2.0$ and 5.0 for these samples. The results appear in Table $V$. The coherent scattering correction is clearly quite small if not negliglble for most cases of interest. 
APPENDIX B

LISTING OF CODE GAHSCT

Code GaMsCT was developed to perform the multipleacattering computations discussed in Section 4 of this raport. Th1s code is written in ASI Standard PORTRN

IV. All code Input is from cards (Unit 4). Output is produced on a teletype (Unit 1) and a line pritnter (Unit 5). The version of this code liated here is operated on a Syatems EngIneering Laboratorles Model 840 iP digital computer. 


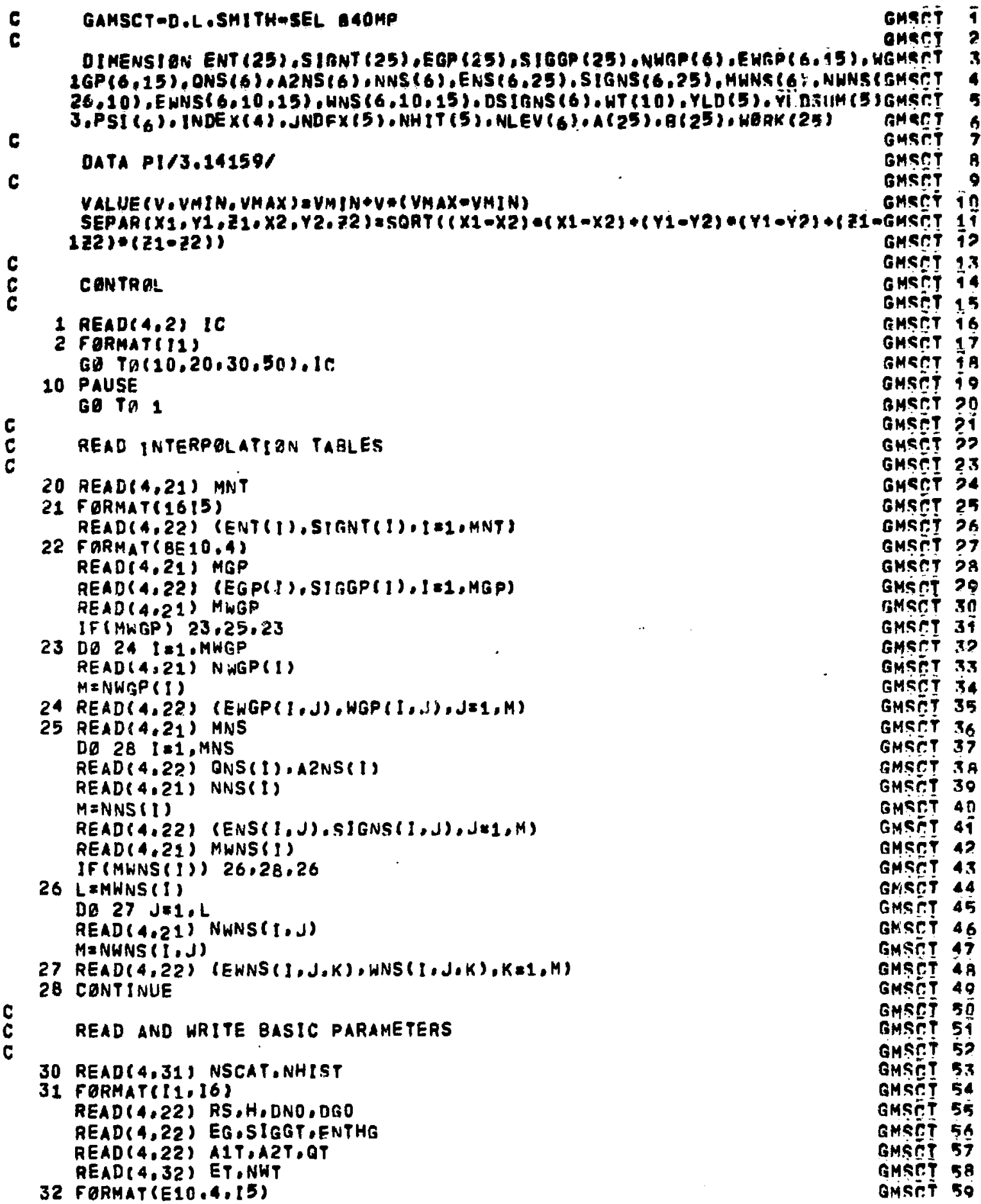


IF (NWT) $34,34,33$

33 READ $(4.22)$ (WT(I),IEI,NWT)

34 WRI PE (5.35) NSCAT. NHIST

35 FQRMAT(1HI/11HNSCAT, NHIST/ 11.16$)$ WRITE $(5,36)$ AS,H,DNO.DGO

36 FERMAT(12HRS,H,DNO,DGO/4EID,4) WRI TE $(5,37)$ EG.SIGGT.ENTHG

37 F ORMAT (14HEG.SIGGT, ENTHG/3E10.4) WAITE $(5,38)$ A1T,ACT, OT

3B FERMAT(1OHA1T.A2T,OT/3E10.1) WRITE (5.39) ET.NWT

39 F ORMAT ( 6 HET, NWT/E10.4.15) IF (NWT) 40.42 .40

10 WRITE $(5,41)$

41 FORMAT (5HWT (I)) WRITE(5.22) (WT(I), $l=1, N W T)$

42 WAITE $(5,43)$

43 FGRMAT(/5H.....)

50 READ $(4,22)$ THTANK WRITE(5.51) THTANK

51 FORMAT(/7HTHTANK $=, E 10.4)$

THDE T $=$ PI + THTANK 180,0

$c$

C

PRELIMINARY CALCULATIONS

RSRS $=R S=R S$

$H H=H * H$

$H D 2=0.5 * H$

RIMIN $=$ DNO $\rightarrow$ RS

R1MAX $=S O R T(D N O * D N O+2,0 * D N O * R S+2.0 * R S R S+0.25 * H H)$

THIMAXEATAN (SORT $(0.25 \cdot H H+R S R S) / R I M I N)$

$V D L 1=2,0$ *D I $(R 1 M A X-R 1 M I N)=T H 1 M A X$

RMAX $=$ SORT (HH+8.0*RSRS)

$V O L H=2,0 \oplus P I * P I * R M A X$

$Y D=D G O N S$ IN (THDET)

$Z D=D N O+D G 0 \circ C O S$ (THDET)

DO $60 \quad 1=1$. NSCAT

$N H I T(I)=0$

60 YLDSUM $(1)=0,0$

DE $61 I=1$, MNS

61 NLEV $(1)=0$

IHIST $=1$

$\mathrm{C}$

C.....START OF HISTORY LEOP

C

C

$100 D 0101 \quad 1=1, N S C A T$

c

101 JNDEX $(I)=0$

C SELECT SCATTERING POINT S(1)

$R=\operatorname{RANF}(-1)$

$R R=V A L U E(R, R I M I N, R 1 M A X)$

$R=R A N F(-1)$

THEVALUE $(A, 0,0$, THIMAX)

$R=R A N F(-1)$

$P H I$ FVALUE $(R, 0,0,2,0, P I)$

GMaret कn

GMSTYT 61

GMSET G?

GMST:T h3

GMSE' की

GMST: 65

GMACET AB

GMST̃ 67

GMSET GA

GMSẼT 69

GM.ST̃T 70

GMsịy ?i

GMSC. 72

GM ST: 73

GMSET 74

GMSẸT 75

GMCet is

GMST̃ 77

GMSCT 7B

GMSẼT 70

GMSET AO

GMSET BI

GMSET a?

GMSeT 83

GMSe' 8

GMST̃T 85

GMaET 86

GMST̄T \&7

GMSET 98

GMSTT 19

GMSET Q0

GMSTिT of

GMSET o?

GMSET 0.3

QMSÉT Q4

GMST̃T 95

GMSET 96

GMSET o7

GMSCT OR

GMSETT 90

GMQC Tित

GMSeTt1

GMSTT1D?

GMSETIDJ

GMarTina

GMSCTiñs

gMserting

GMSCT107

GMSCTIOA

GMSṬT̃O

GMSET110

GMSTT11

GMSTT11?

GMST T1

GMSET11A

GMSET115

GMSET 196

GMSẸTㄱำ

QMeET198

omsกี่วิด 


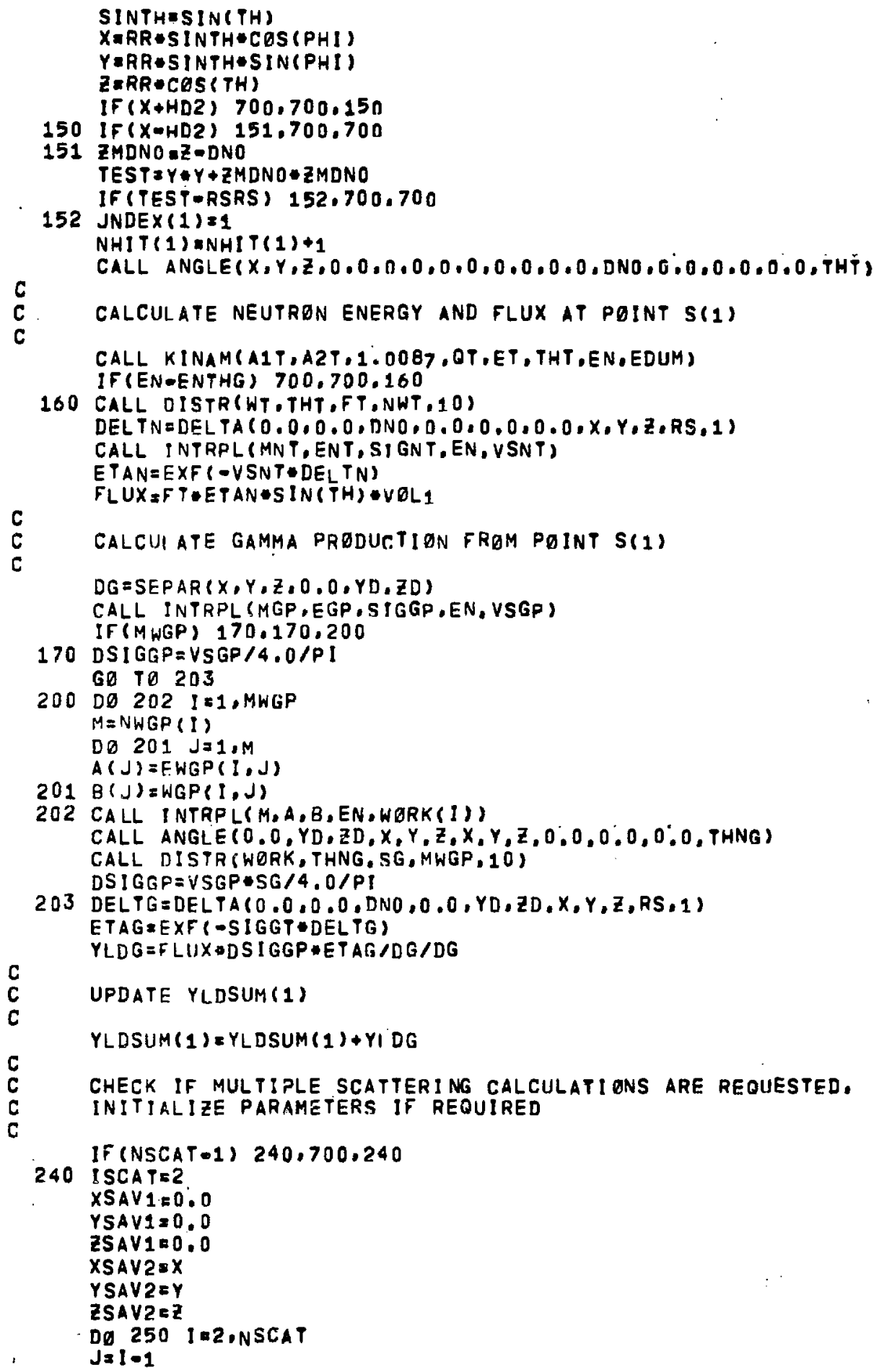

GMลคำ1ำ GMSTT1? OMSET1?? GMSCT1D3 GMCกัT1ร4

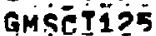
GMECT126 QMSÉT127

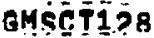
GMST́T120 GMSCT13은 GMSET 134 GMSE.T1.3? GMSET 133 GMSTTY 134 GMSr:T135 GMSET 136 GMSPT137 GMSCT13月 GM Srẹ 130 GMSCT 140 GMSก:T14 GMsćt 1 4? GMST̃:T 143 GMSTिT144 GMSĈT 45 GHSCT: 16 GMSTT147 GMŚT̄ 148 GHSTI1 49 GHSET150 GMSṬT154 GMSET152 GMSET153 GMSC 154 GMSET155 GMSET156 GMSc̃T 157 GM⿻ำ 15A GMSTT150 GMsễiton GMSCT 161 GHSCT16? GMSẼTIAX GMSCT164 GMSCT165 GMSCI 166 GMSẼ 167 GMSCT16B GMSกт160 GMSCT170 CMSC 177 GMSCT17? GMSE得3 GMSC:T174 GMSETI75 GMSET176 GMsR.T177 GMSET17月 GMSAT170 


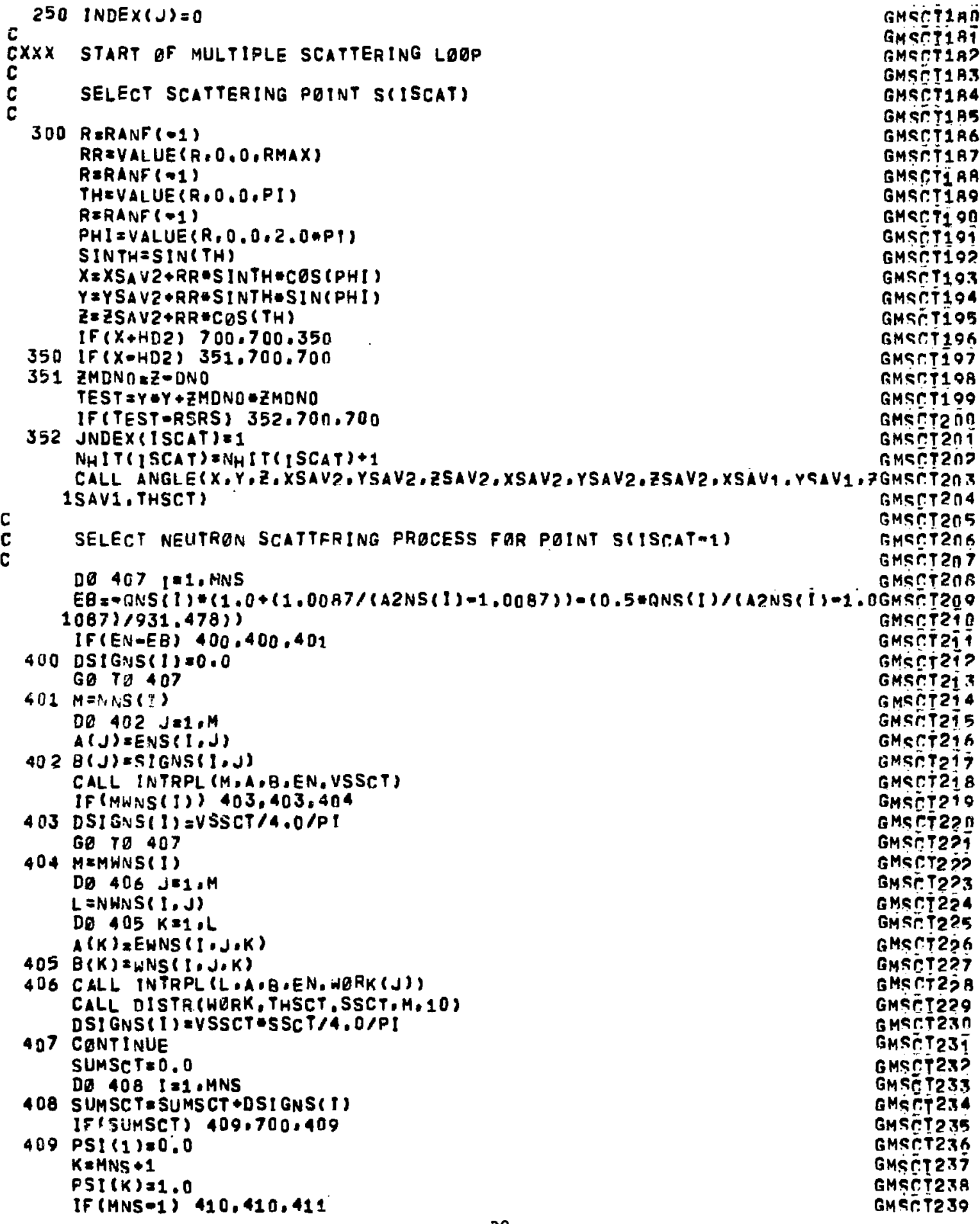


410 1NDX:1

OD TD 414

411 SUMPS $I=0.0$

DO 413 I 22 . MNS

$J: I=1$

SUMPSI ISUMPS I+DSIGNS(A)

PSI $(I)=S U M P S I / S U M S C T$

IF (PSI (I)-1,0) $113,413,412$

412 PSI $(1)=1.0$

413 CONTINUE

$R=R A N F(-1)$

CALL FINDI(PSI,K, G,R, INOX)

C

414 NLEV (INDX) $=$ NLEV (INDX) +1

amscrean

GMSr.T241

GMSET24?

GMSET 243

GMSET244

GMSẼT245

GMSCT246

GMSTT247

GMSET24B

GMSTY?249

GMSTiti25n

GMSTrT25

GMç่:T25

GMSCT25.3

GMscit25.

CALCULATE NEUTREN ENFRGY AND FLUX AT PGINT S(ISCAT)

GMSTrT25s

500 ENSAV $=E N$

GMSCT256

CALL KINAM(1.0087, A2NS(INDX),1.0087, ONS(INDX),ENSAV, THSCT, EN. FDUM)GMSFT257

$1 F$ (EN-ENTHG) 700.700.501

501 CALL INTRPL (MNT,ENT,SIGNT,EN, VSNT)

ETAN=EXF (-VSNT:RR)

FLUX $=F L U X * S U M S C T * E T A N * S I N(T H)=V Q L H$

GMSCT258

GMSCT250

GMSCTि2A?

GMSET261

GMSETि2GD

Calculate gamma productian from paint s(ISCat)

GMST̃T263

GMSTT2A4

$D G=\operatorname{SEPAR}(X, Y, Z, 0,0, Y \cap, Z D)$

CALL INTRPL (MGP,EGP,SIGGP,EN, VSGP)

IF (MWGP) 502.502 .600

502 DSIGGP =VSGP/4.0/PI

GO TO 603

GMSCT265

GMSCT2AB

GMSETTAT

GMECT2A

GMST̃T260

GMSri27n

GMSËT27!

GMSTIT25

$M=N W G P(I)$

D0 $601 \mathrm{~J}=1, \mathrm{M}$

$A(J)=F W G P(1, J)$

$601 B(J)=W G P(I, J)$

$602 C A L L$ INTRPLS M, A,B,EN,WORK(I),

CALL ANGLE $\left(O, O, Y D, Z D, X, Y, Z, X, Y, Z, X S A V_{2}, Y S A V_{2}, Z S A V D, T H N G\right)$

CALL DISTR(WORK, THNG,SG, MWGP,10)

$D S I G G P=V S G P \square S G, 4,0 / P$ I

603 DELTG $=D E L T A(0,0,0,0, D N O, 0,0, Y D, Z D, X, Y, Z, R S, 1)$

$E T A G=E X F(-S I G G T \bullet D E L T G)$

$Y L D G=F L U X * D S I G G P * E T A G / D G / D G$

$\mathrm{C}$
$\mathrm{c}$
$\mathrm{C}$

UPDATE YLDSUM(ISCAT) AND FIX INDEX(ISCAT-1)

YLDSUM(ISCAT) =YLDSUMIISCAT) +YLDG

$J=I S C A T=1$

INDEX $(J)=I N D X$

$c$
c
c

TEST FOR END OF MULTIPLE SCATTERING LOGP, RESET PARAMETERŚ F́丶 NEXT CYCLE IF REQUIRED

ISCAT EISCAT+1

IF(ISCAT-NSCAT) $610,690,700$

610 XSAV1 =XSAV2

YSAVI = YSAV2

ZSAV1 =ZSAV2

XSAVZ EX

YSAVZ $=Y$

ZSAVZ $=Z$

GMSTिT273

GMSTYT2

GMSET275

GMSCTP Th

GMSTिT7

GMSCITia

GMSTrTzio

GMSET2AD

GMST́T28i

GMCCT2AO

GMST:?2A3

GMSít?aA

GMSÉT2A5

GMSCT2AS

GMSCTT2A7

GMSCT 2 A

GMSCTT280

GMECT200

GMSFTT291

GMSCI292

GMSẼT203

SMSET204

GMsiñ? 295

GMSCT206

GMSET 297

GMCET208

GMETY 200 


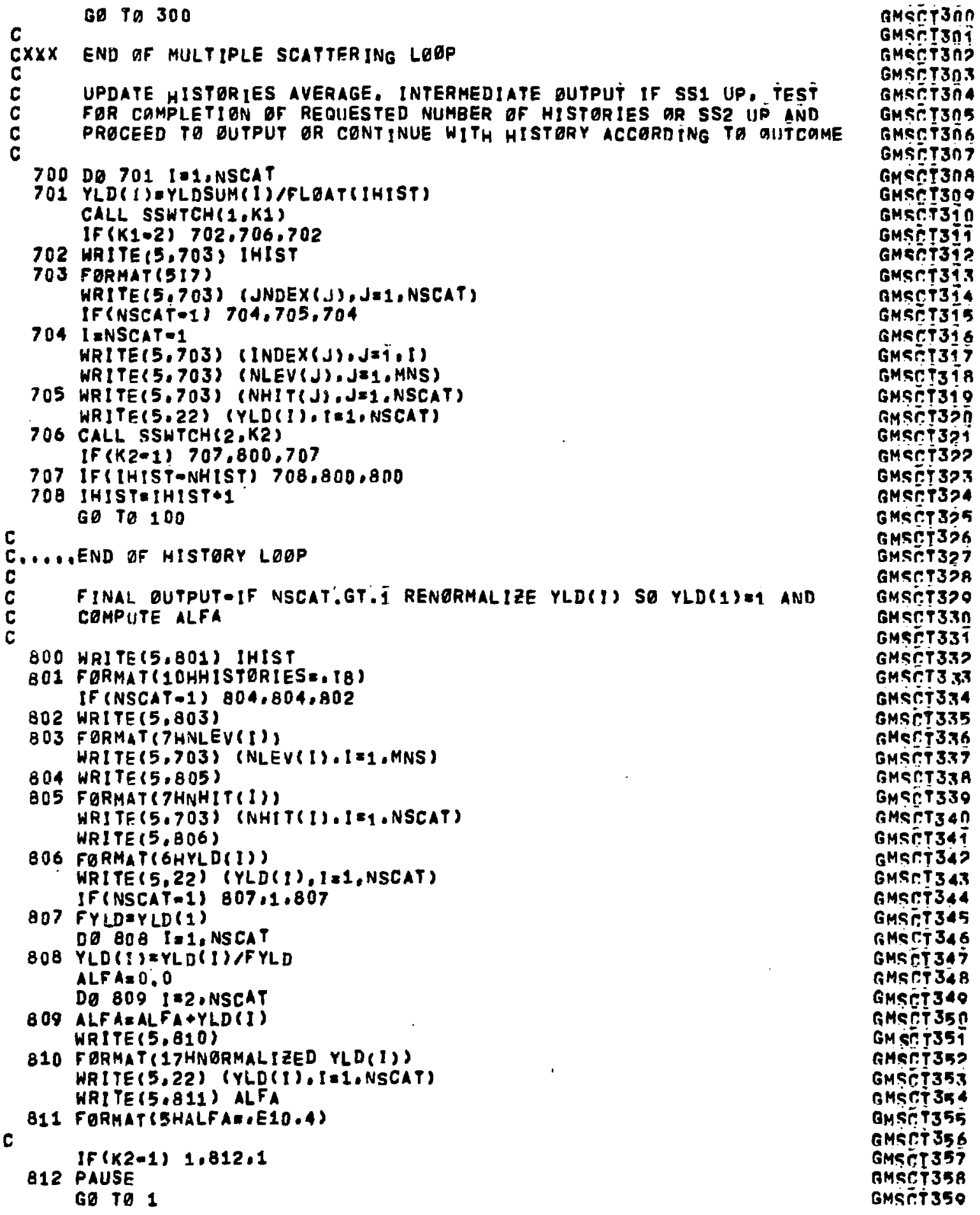




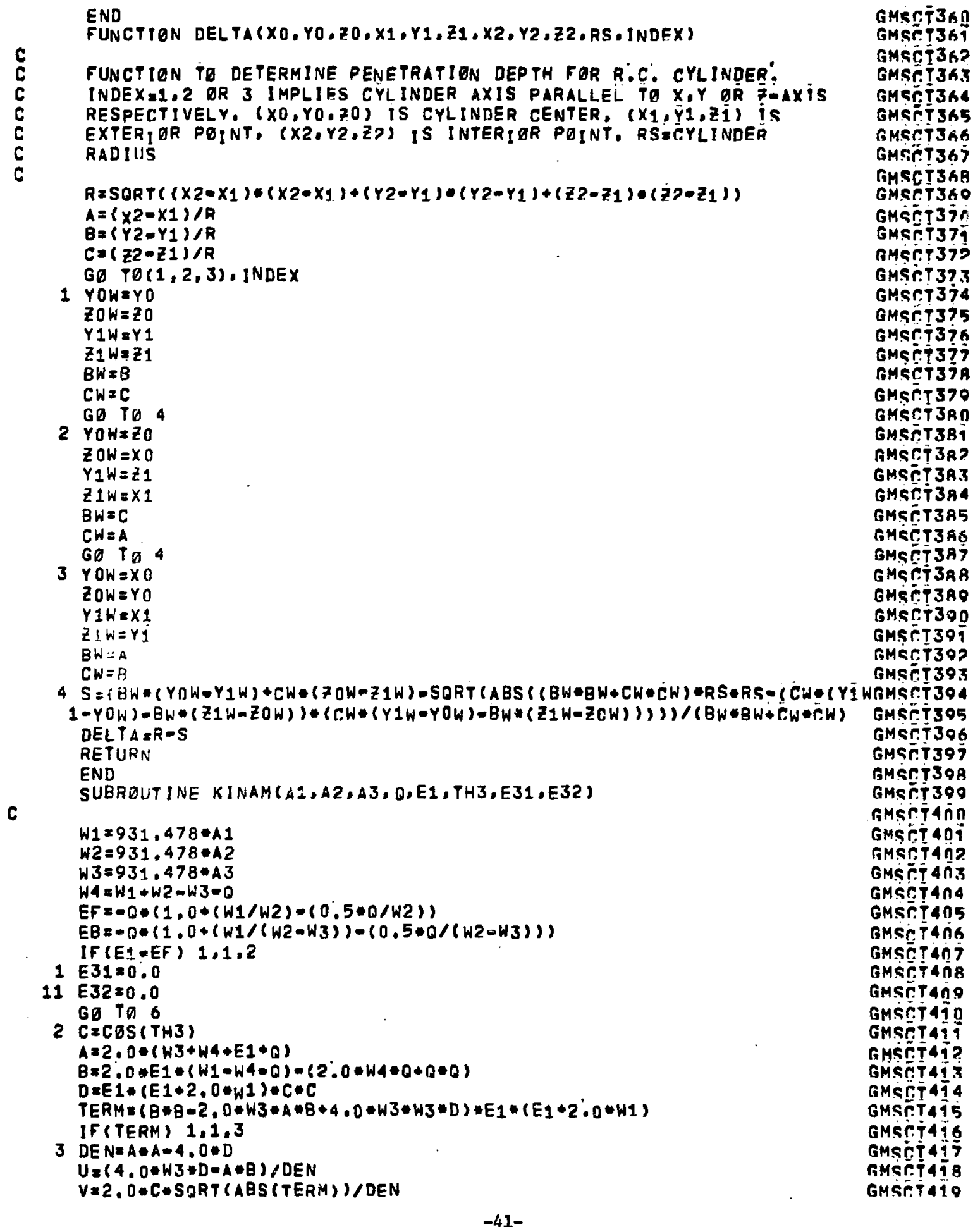




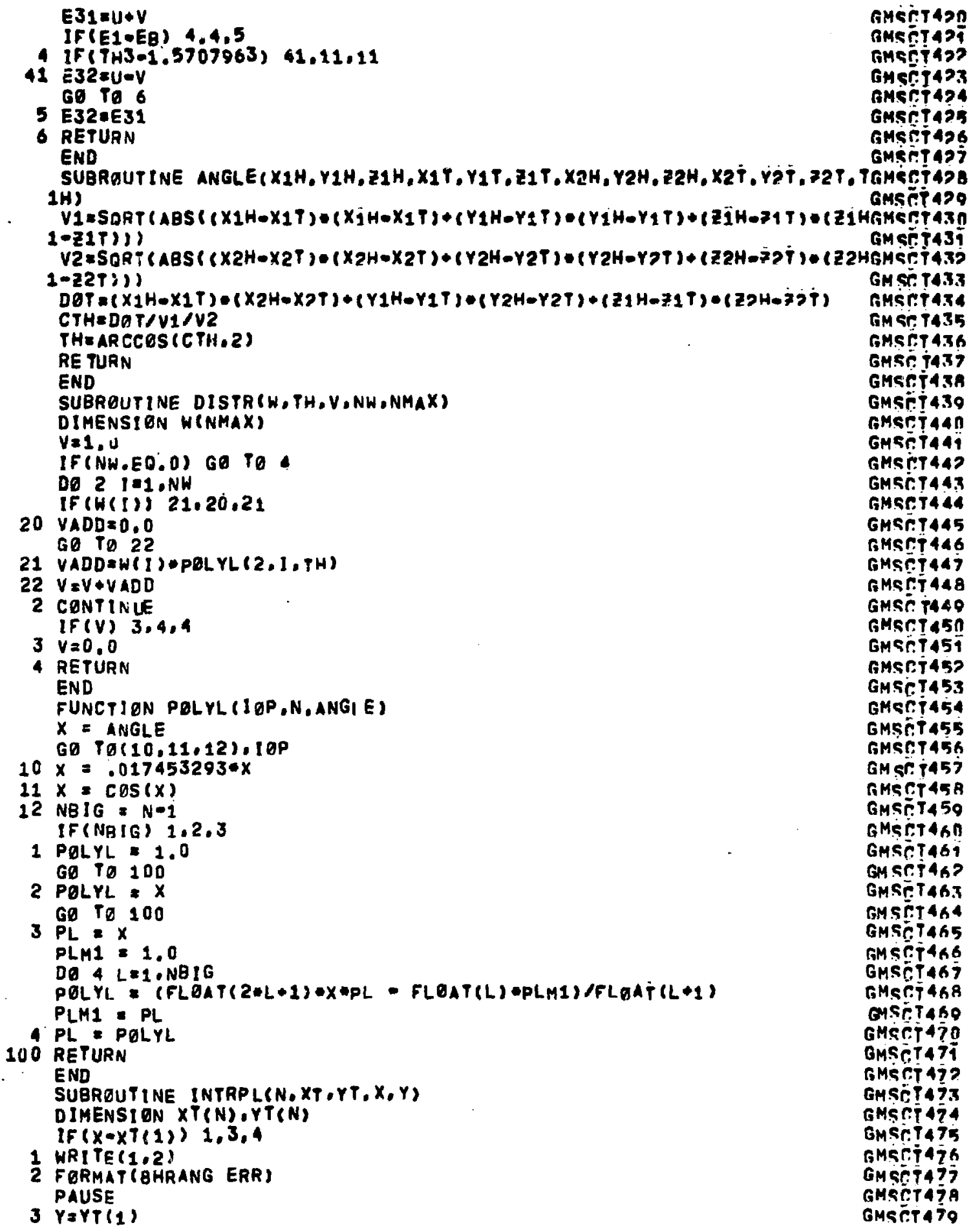




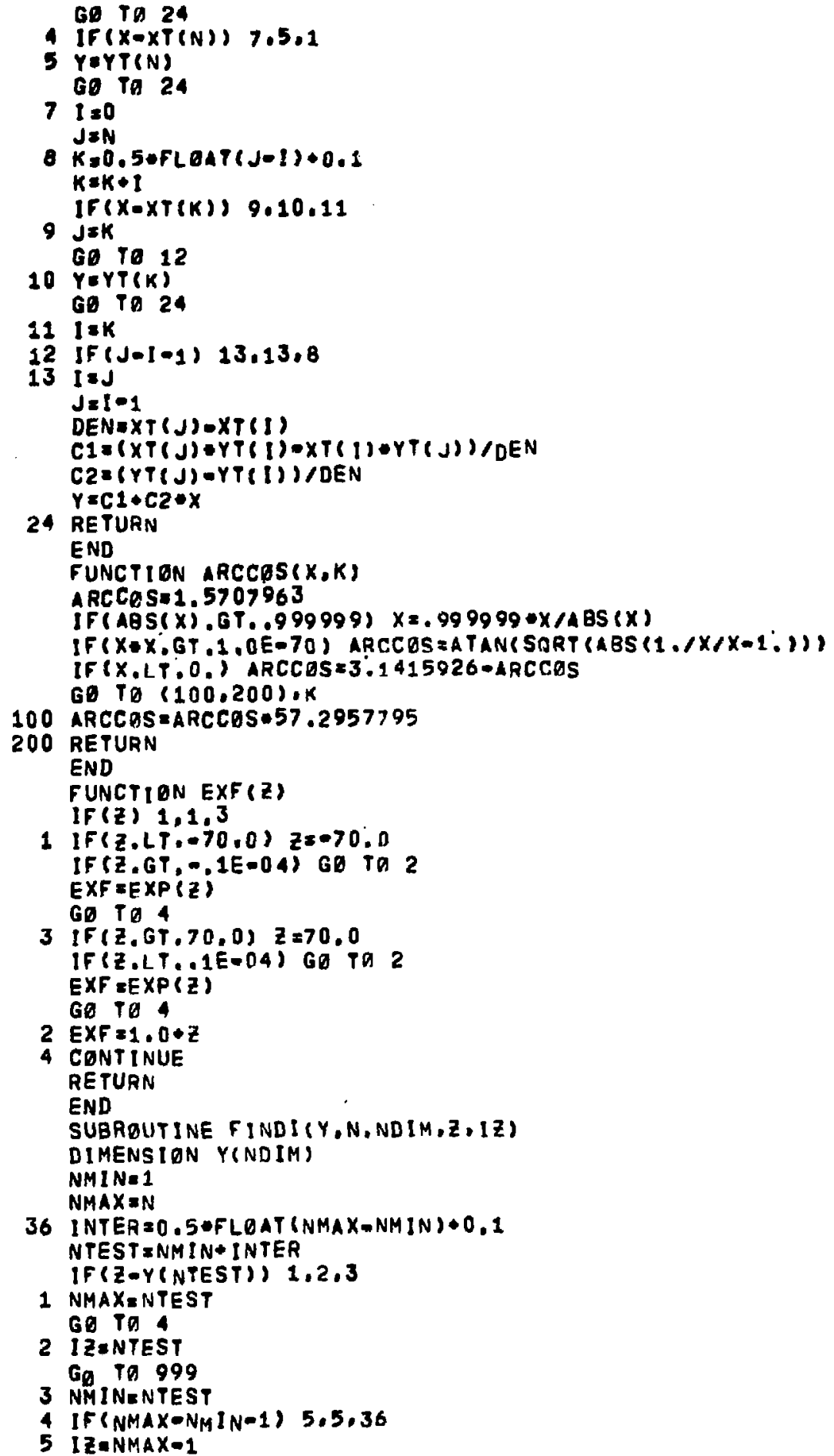

RMEẼ YAAn GMSṔt AnT GMartAR? GMSTY TA3 GMGC.TAMA GMSET 4 AS GMERTAAG GMét4A7 GMSC̄TARR GMSETAAO GMSc. 400 GMSET T49 GMEC 40 ? GMSET 493 GMSET 494 GMSP T495 GMECT4OA GMsT.T407 GMÉ̃ TीQ AMECT490 ométínn GMétsni GMerTSn? GMSerson aMerT5n GMSETSAs GMECTsing Gmsettsny GMét GMSreT5D? GMCrT5 GMSr.t5it GMSPTSi? GMSCTS 13 GMACT̄5̆ GMSĆTร GMarT5i6 GMSCTS17 GMSR.T51A GMSRTSTO GMSCT520 GM SCT5?1 GMACT5D 6M.SCिT5ว GMECP5० GMSCYYSD GMSCT5D GMCё7507 GMETंग GMS TिT5ว0 GMSCT53n GMSCT5x G MSCT532 GMSêt53.3 GMSê. 5.54 GMSR̈T5.35 GMśc广5. GMSET T537 GMAR:T53A GMSế. 530 
999 RETURN

END

GMsétsan
GmertTs iq

$\mathbf{s}$

GMert54?

$-44-$

Nint - . 
1. Donald L. Smith, Report ANL/NDM-12, Argonne National Laboratory (1975).

2. S. A. Cox and P. R. Hanley, IEE Trans. Nucl. Sci. 18, 108 (1971).

3. R. B. Day, Phys. Rev. 102, 767 (1956); Progress in Fast Neutran Physics, edited by G. C. Phillips, I. B. Marton and J. R. Risser (University of Chicago Press, Chicago, 1963).

4. K. Nishimura, K. Okano and S. Kikuch1, Nucl. Phys. 70, 421 (1965).

5. J. B. Parker, J. H. Towle, D. Sams and P. G. Jones, Nuc1. Instr. 14, 1 (1961).

6. S. A. Cox, Nuc1. Instr. 56, 245 (1967).

7. O. Aspelund and B. Gustafsson, Nucl. Instr. 57, 197 (1967).

8. P. Kuijper, J. C. Veefkind and C. C. Jonker, Nucl. Instr. 77, 55 (1970).

9. W. E. Kinney, Nuc1. Instr. 83, 15 (1970).

10. J. K. Dickens, Nuc1. Instr. 98, 451 (1972).

11. S. A. Elbakr, I. J. Van Heerden, W. K. Dawson, W. J. McDonald and G. C. Nellson, Nucl. Instr. 97, 283 (1971).

12. B. Minetti and A. Pasquareili, Nucl. Instr. 120, 509 (1974).

13. E. D. Cashwe11, C. J. Everett and O. W. RAchards, "A Pract1cal Manual on the Monte-Carlo Method for Random Walk Problems," Regort LA-2120, Los Alamos Scientific Laboratory (1957).

14. Evaluated Neutron Data F1le, ENDF/B-IV, NatIonal Neutron Cross Section Center, Brookhaven National Laboratory.

15. E. Storm and H. I. Israe1, Nuc1. Data Tables A7, 565 (1970). 


\section{Table I}

\section{Nominal Conditions Considered in Sample Geometry and Absorption Calculations}

\section{Geometry:}

$$
\begin{aligned}
& R_{S}=1.9 \mathrm{~cm}, H=-3.8 \mathrm{~cm}, D_{n}=12.8 \mathrm{~cm}, \\
& D_{\gamma}=130.0 \mathrm{~cm}, a=0.5 \mathrm{~cm}, \text { various } \theta_{D E T}
\end{aligned}
$$

Mesh s1ze:

$$
n_{T}=1, n_{H}=5, n_{R}=5, n_{\phi}=3
$$

Sample material and gamma ray:

$$
\text { Natural Iron, } \mathrm{E}_{\gamma}=0.846 \mathrm{MeV}
$$

Neutron Bource:

$$
\text { Isotroplc yleld, } Q=0, A_{1}=1, A_{2}=7 \text {. }
$$

Incident energy selected so $\mathrm{E}_{n, \max }=1 \mathrm{MeV}$. Crose aections ${ }^{a}$ :

$$
\begin{aligned}
& \Sigma_{n T}=0.27, \Sigma_{\gamma T}=0.5 \\
& (d \sigma / d \Omega)_{\gamma}=0.038 \mathrm{~b} / \mathrm{sr} \text { (1sotropic) }
\end{aligned}
$$

Gamma-detector efficiency:

Arbitrary constant value

a These are nominal values which are not necessarily equal to ENDF/B-IV values for iron. 
Table II

Computed Yield Ratios Which

Demonstrate the Effects of

Geometry and Radiation Absorption

$$
\begin{array}{ll}
\text { "Front" - to } & \text { "Near" - to } \\
\text { "back" ratio } & \text { "far" ratio" }
\end{array}
$$

1) Neutron and gamma-ray absorption

2.11

2.11

11) Gamma-ray absorption only

1.19

2.19

111) Neutron absorption only

1.78

1.03

iv) No absorption

1.16

1.02

a Ratios are defined in Section 3.2. 
Table III

\begin{tabular}{|c|c|c|}
\hline \multicolumn{3}{|c|}{ Dependence of Gama-Ray } \\
\hline & he $S$ & Radius \\
\hline$\underset{(\mathrm{cm})}{\mathbf{R}_{\mathbf{S}}}$ & $\overline{\mathbf{Y}}_{0}^{\mathrm{a}}$ & $R_{S} \bar{Y}_{0}{ }^{a}$ \\
\hline 0.635 & 1 & 1 \\
\hline 0.95 & 0.84 & 1.25 \\
\hline 1.27 & 0.70 & 1.41 \\
\hline 1.59 & 0.60 & 1.50 \\
\hline 1.905 & 0.52 & 1.55 \\
\hline 2.54 & 0.39 & 1.57 \\
\hline
\end{tabular}

a $\bar{Y}_{0}$ computed for $\theta_{D E T}=90^{\circ}$. Values are relative to corresponding values for $R_{S}=0.635 \mathrm{~cm}$. 
Table IV

Nominal Condttions Considered in

Sample Mult1ple Scattering Calculations

\section{Geometry:}

$$
\begin{aligned}
& R_{S}=1.9 \mathrm{~cm}, \mathrm{H}=3.8 \mathrm{~cm}, D_{n}=11.4 \mathrm{~cm}, \\
& D_{\gamma}=130.0 \mathrm{~cm} \text {, Various } \theta_{D E T}
\end{aligned}
$$

Sample material and gamma ray:

Natura1 iron, $E_{\gamma}=0.846 \mathrm{MeV}$

Neutron source:

Isot ropic yield, $Q=0, A_{1}=1, A_{2}=$ very 1 arge.

Neutron energy $E_{n}=2 \mathrm{MeV}$.

Crosg sections ${ }^{a}$ :

$\Sigma_{\mathrm{nT}}=0.17$

Elastic scattering, $Q=0, A_{1}=1, A_{2}=55.85$,

$\Sigma_{\text {EL }}=0.17$ (isotropic)

Inelastic scattering, $Q=-0.85 \mathrm{MeV}, A_{1}=1, A_{2}=55.85$, $\Sigma_{\text {IN }}=0.05$

$(\mathrm{d \sigma} / \mathrm{d} \Omega)_{\gamma}=0.038 \mathrm{~b} / \mathrm{sr}$ (isotropic)

a These are nominal values which are not necessartly equal to ENDF/B-IV values for iron. 


\section{Table V}

Fffect of Coherent Photon Scattering

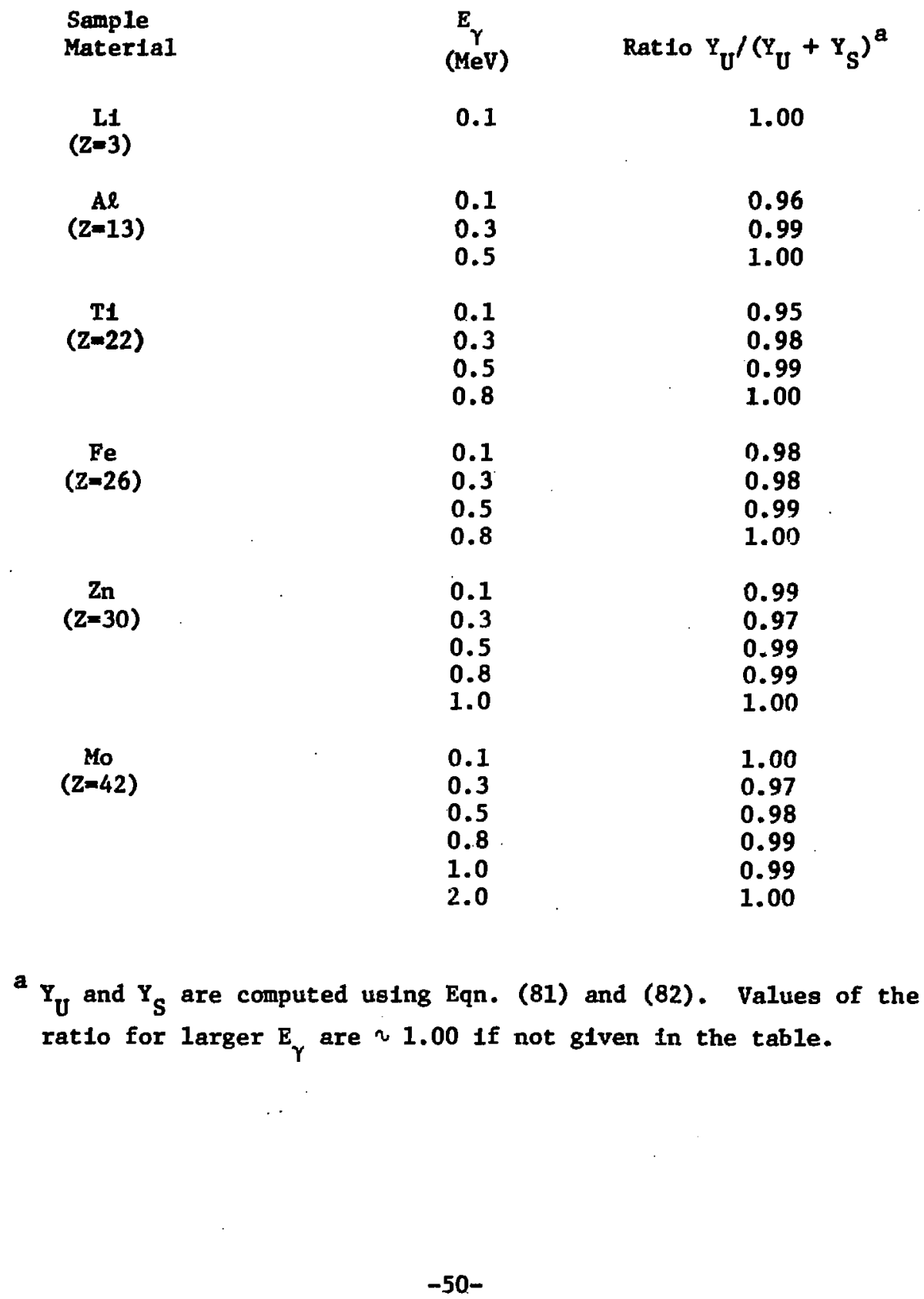


FIGURE CAPTIONS

F1g. 1. The tocal cross section for natural iron in the energy range 0.1-2 MeV. The solid curve represents ENDF/B-IV values [14] . The dashed curve represents the same information after smoothing with a $0.1-\mathrm{MeV}$ resolution function. The smoothed excltation function can be approximated by connecting the large dots with straight line segments. This simulstes linear interpolation of a lookup table which is stored in the memory of a digital computer. (ANL Neg. No. 116-75-91).

Fig. 2. Schematic diagrams to illustrate geometry applicable to computation of the yleld of gamma-rays from $\left(n, X_{Y}\right)$ reactions produced by unscattered neutrons. (ANL Neg. No. 116-75-89).

Fig. 3. Distortion of an 1sotroplc gamma-ray production angular distribution by radiation absorption. (ANL Neg. No. 116-75-85).

F1gs.4 Sample mfüplane relative-yleld profiles for the following rethru Fig. 7 spective conditions: 1) neutron and gamma-ray absorption, 11) gamna-ray absorption only, 111) neutron absorption only, and iv) no absorption. (ANL Neg. Nos. 116-75-84, 116-75-88, 116-75-86, 116-75-82).

Fig. 8. Computed angular resolution functions for several values of $\theta_{\mathrm{DET}}$ and Table I parameters. (ANL Neg. Nos. 116-75-80).

Fig. 9. Demonstration of the factorization rule. The solid lines represent assumed differential cross section functions while the solid circles represent values of $\overline{\mathrm{Y}}_{0} /\left(1-\Delta \cos \theta_{D E T}\right)$ for various $\theta_{\mathrm{DET}}$ but plotted at the corresponding angles $\left\langle\theta_{\mathrm{n} \gamma}\right\rangle$. All results are normalized to unity at $\theta_{D E T}=90^{\circ}$. (ANL Neg. No. 116-75-87).

Fig.10. Geometry appropriate to multiple-scattering calculations for the first two scattering orders. (ANL Neg. No. 116-75-92).

Fig.11. Plot of relative values for $Y_{0}, Y_{1}, Y_{2}$ and $Y_{3}$ computed using the parameters in Table IV. (ANL Neg. No. 116-75-90).

Fig.12. Plots of $\alpha_{1}, \alpha_{2}, \alpha_{3}$ and $\alpha_{\text {TOT }}$ for various sample sizes $\left(H=2 R_{S}\right)$. (ANL Neg. No. 116-75-83).

Fig. 13. The relative yield of $0.846-\mathrm{MeV}$ gamma rays per atom for various natural iron samples. Comparison is made between the experimental results and the results of four sets of computations described in Section 5. (ANL Neg. No, 166-75-81). 


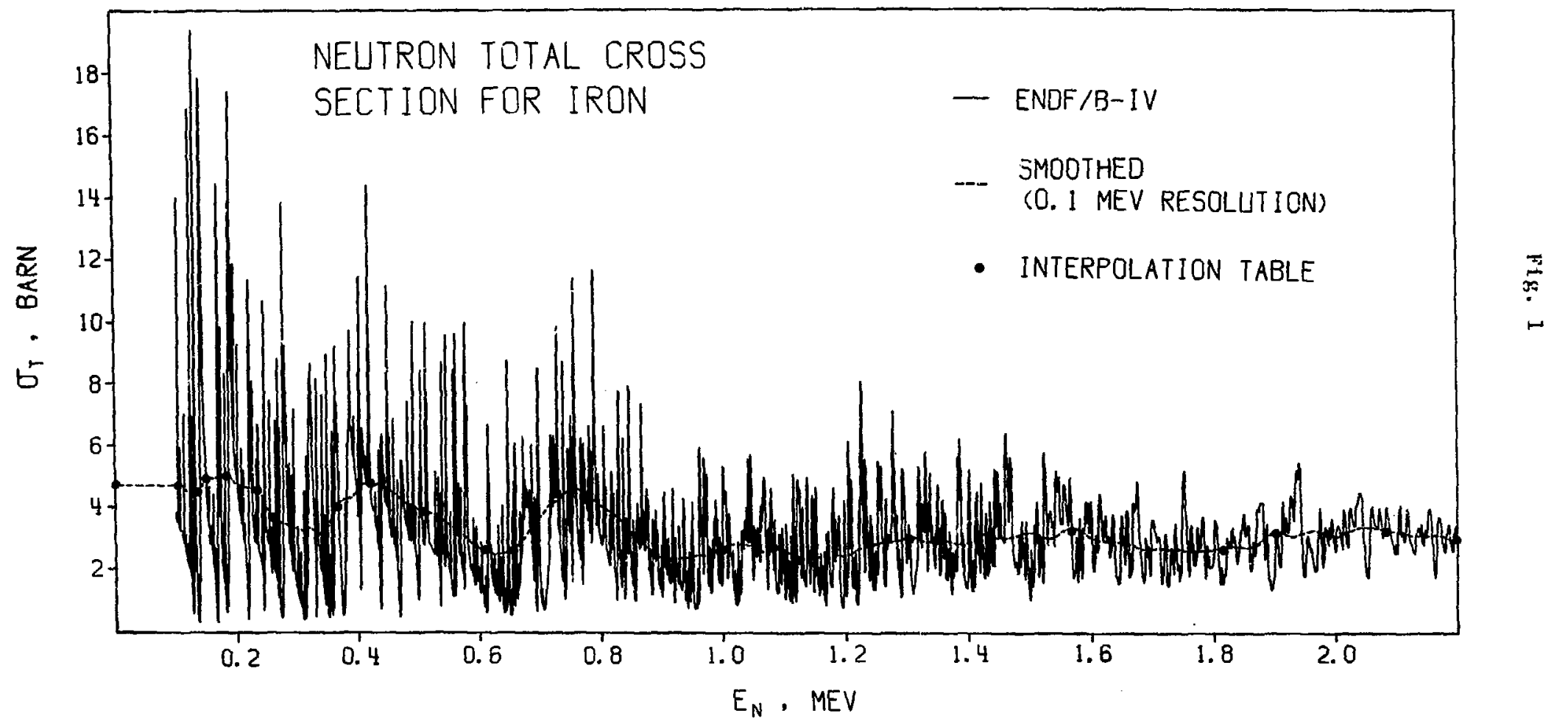


Fig. 2

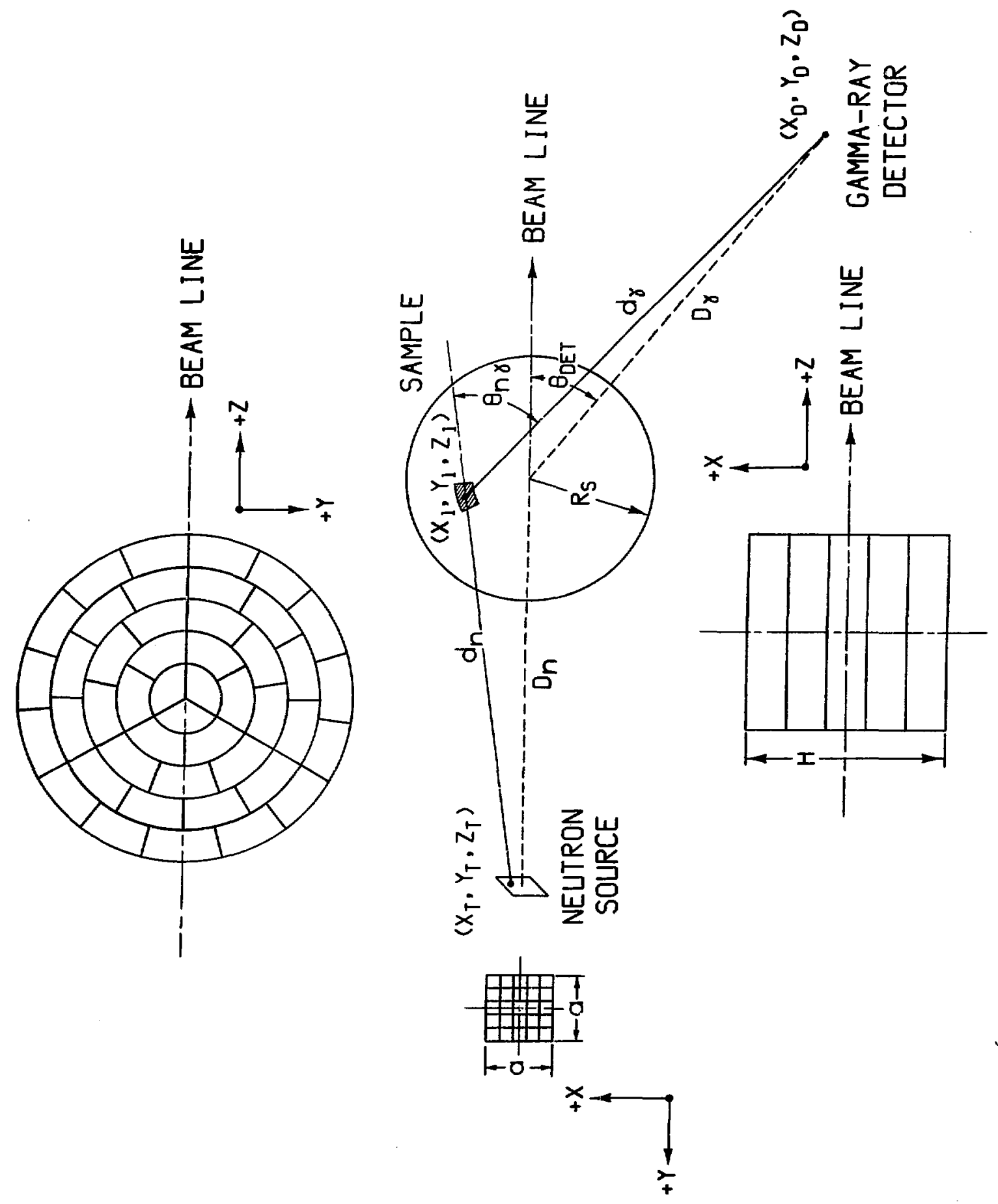




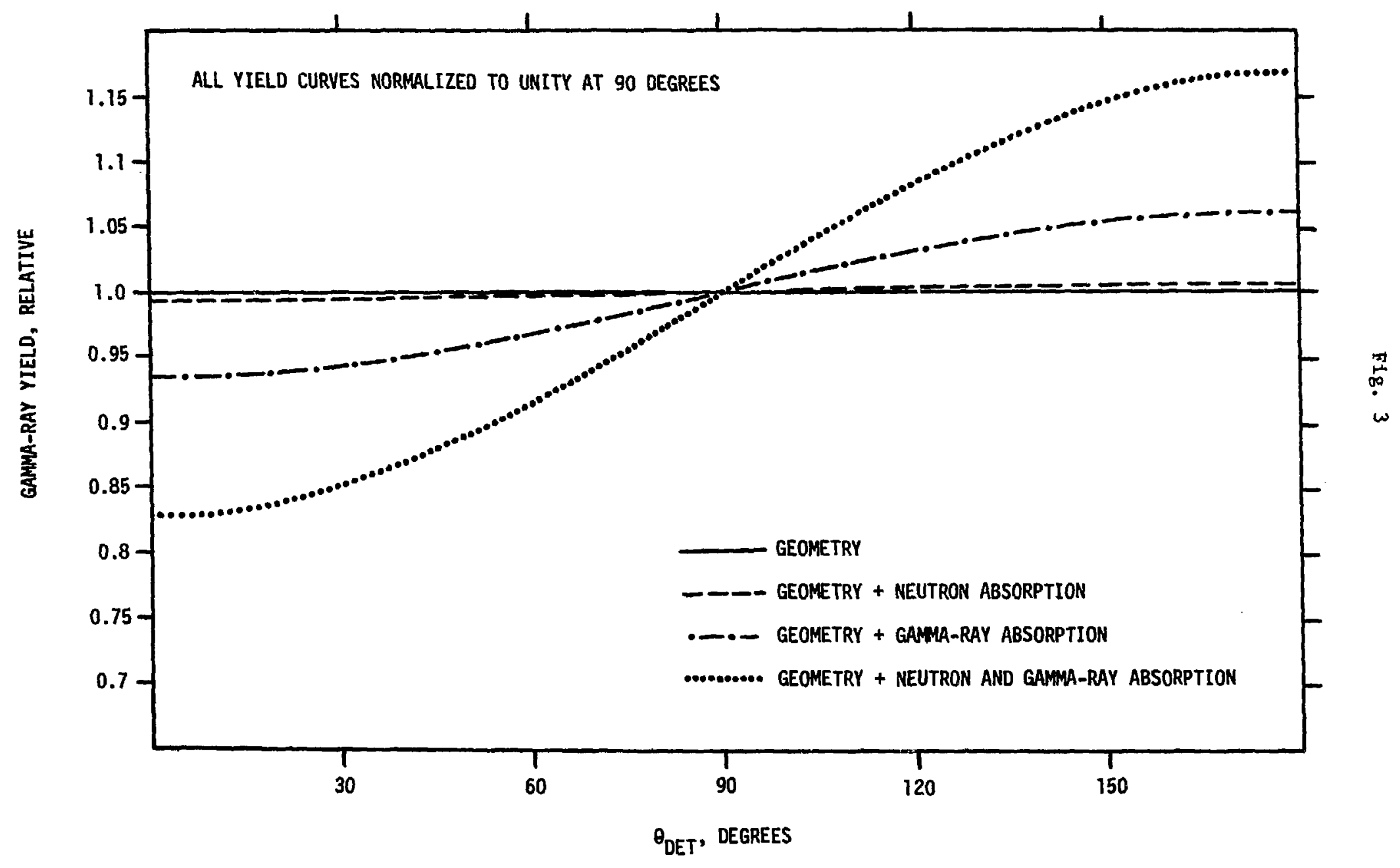


Fig. 4

NEUTRON AND GAMMA-RAY ABSORPTION
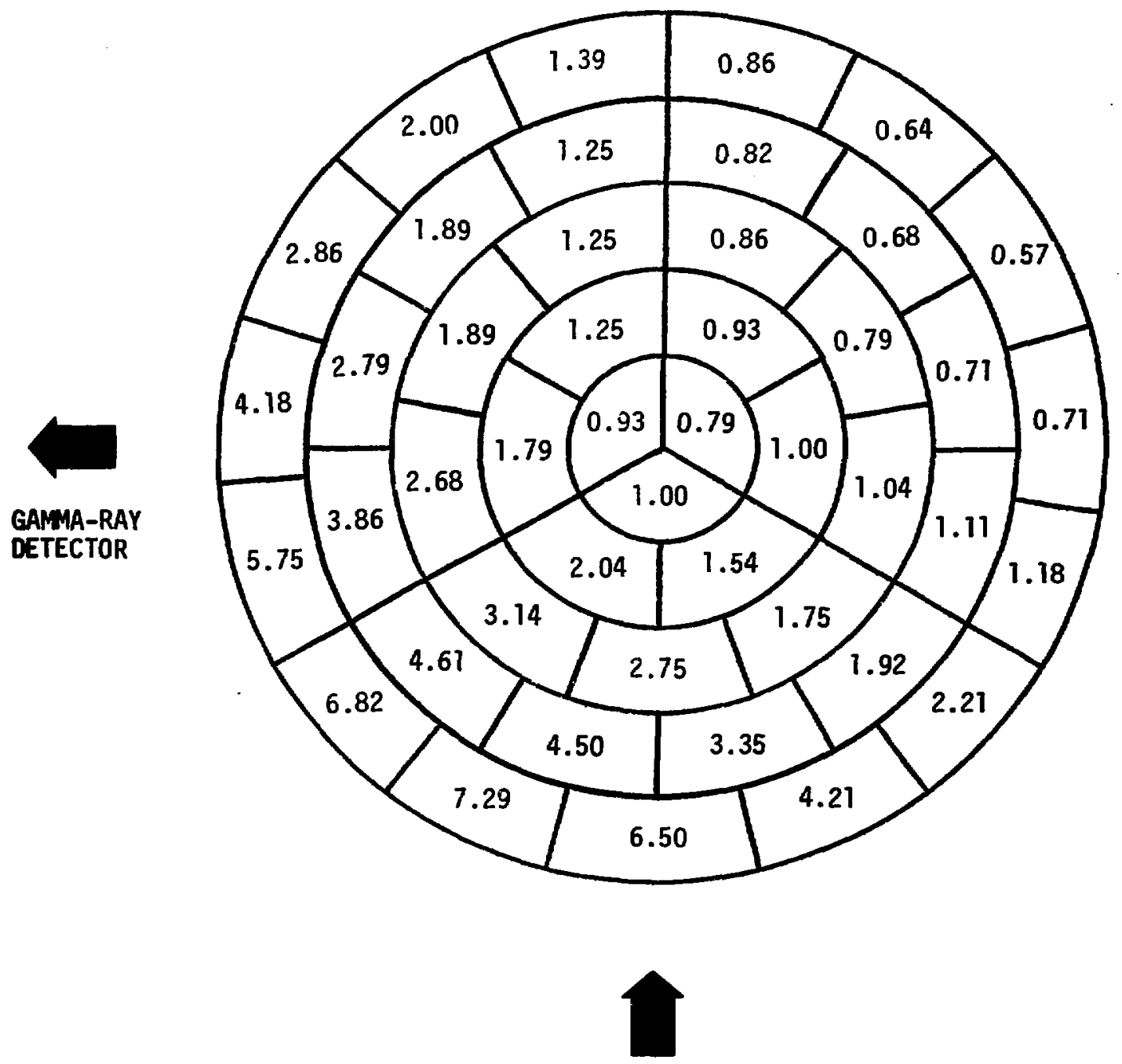

INCIDENT

NEUTRONS 
Fig. 5

GAMMA-RAY ABSORPTION

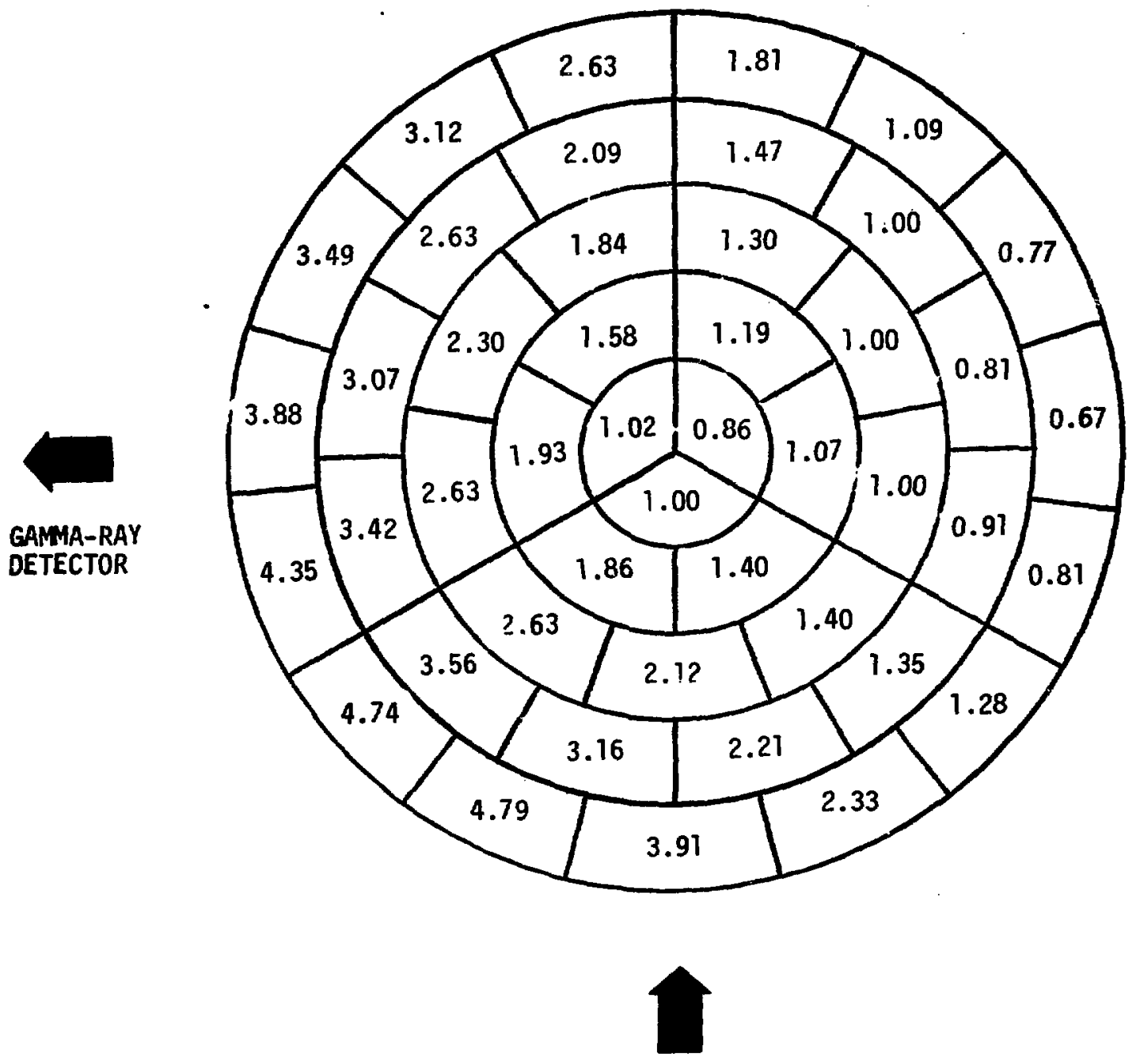

INCIDENT

NEUTRONS 
Fig. 6

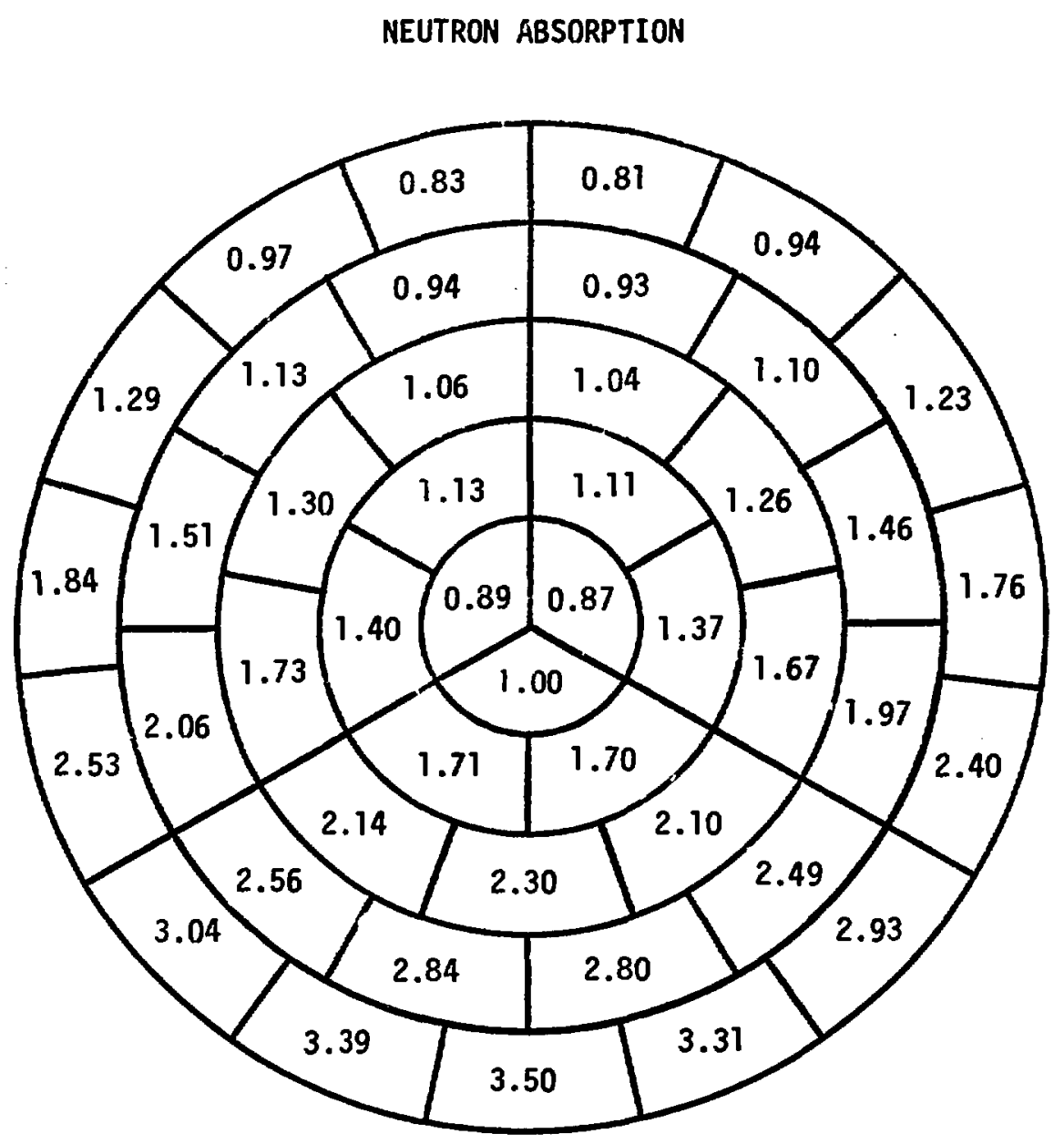

INCIDENT

NEUTRONS 
Fig. 7

NO ABSORPTION

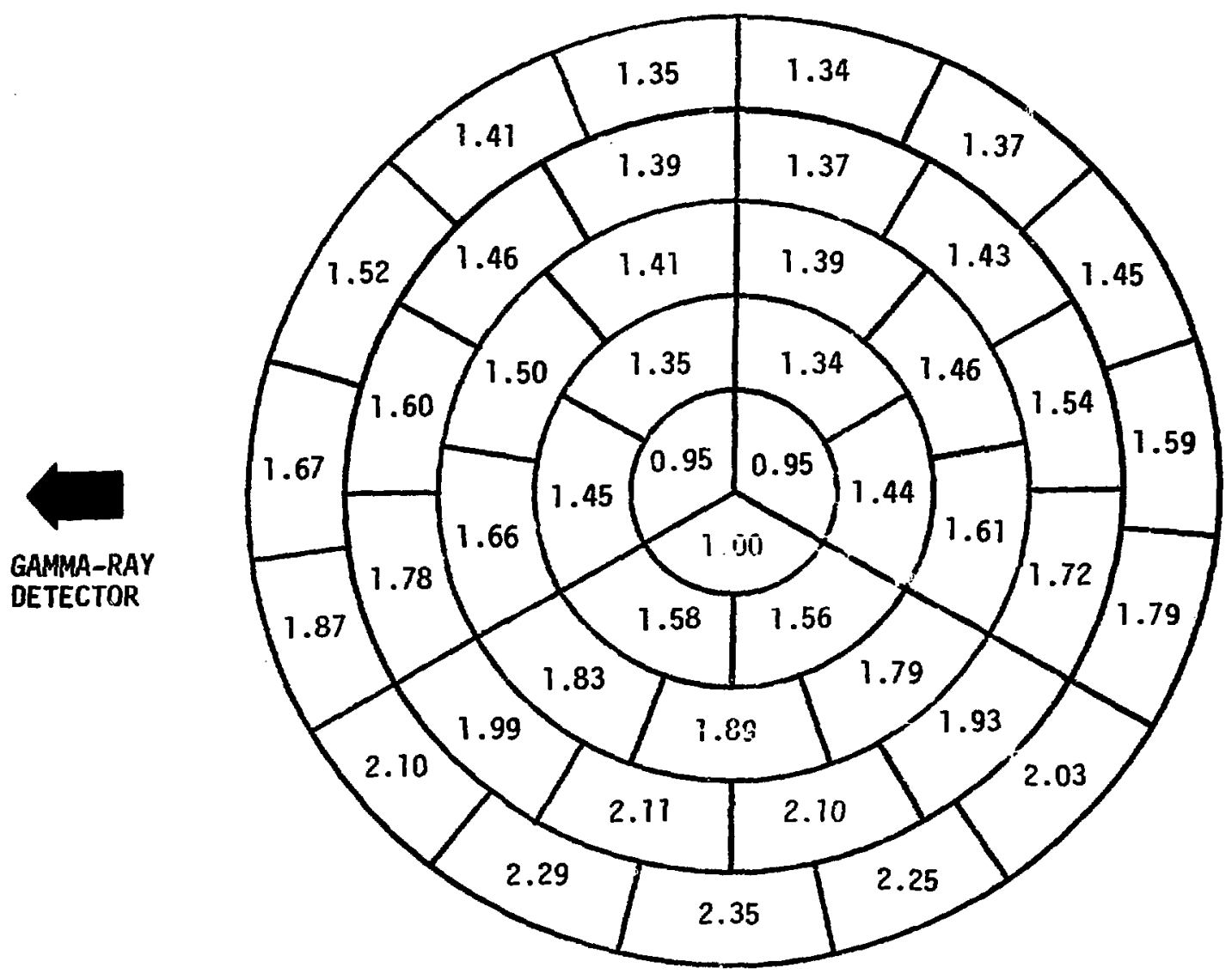

INCIDENT

NEUTRONS 
Fig. 8
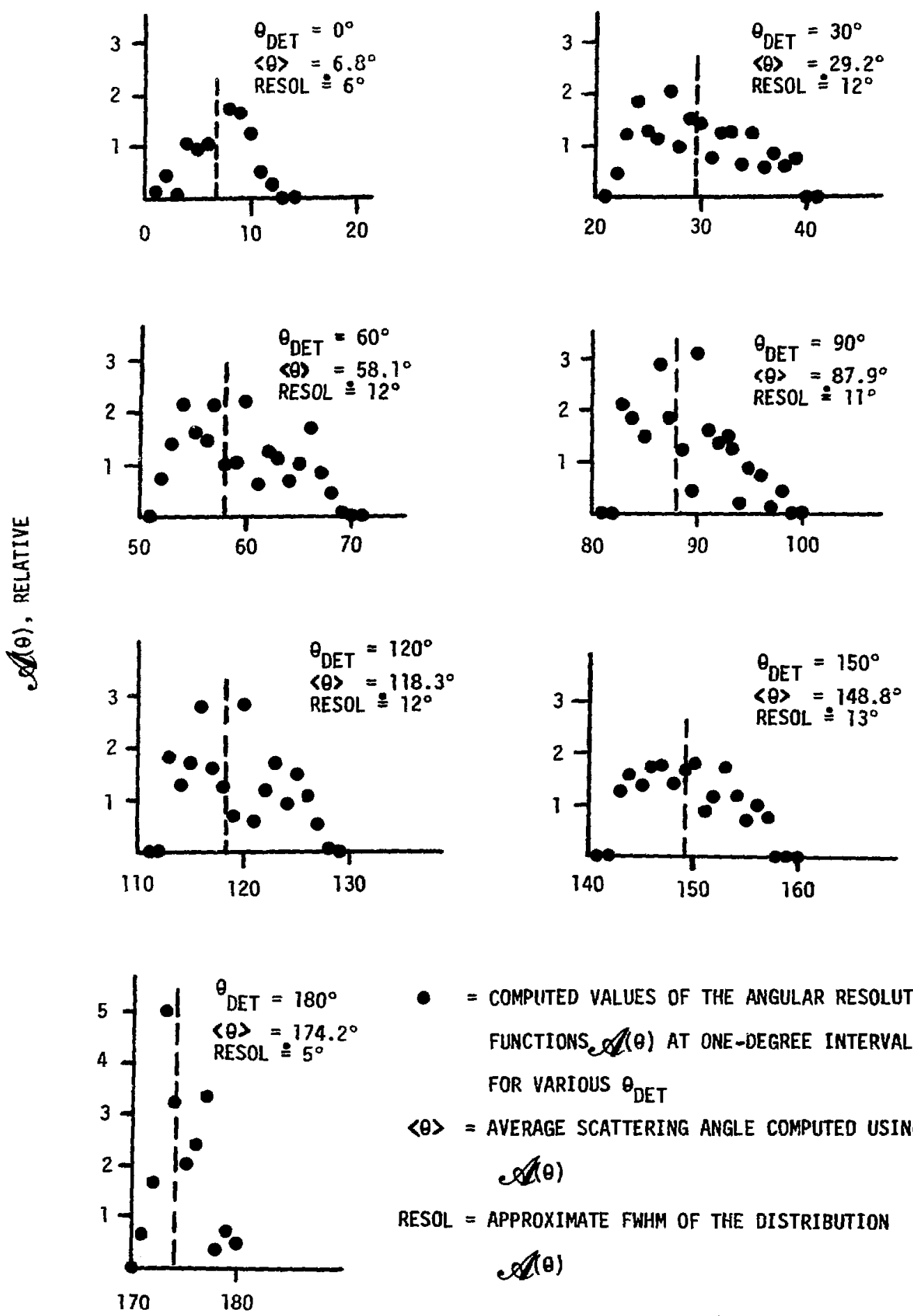

- = computed values of the angular resolution FUNCTIONS $\mathscr{A}(\theta)$ at ONE-DEgREE INTERVALS FOR VARTOUS $\theta_{\text {DET }}$ $\langle\theta\rangle=$ AVERAGE SCATTERING ANGLE COMPUTEO USING C(A) RESOL = APPROXIMATE FWHM OF THE DISTRIBUTION (2) 


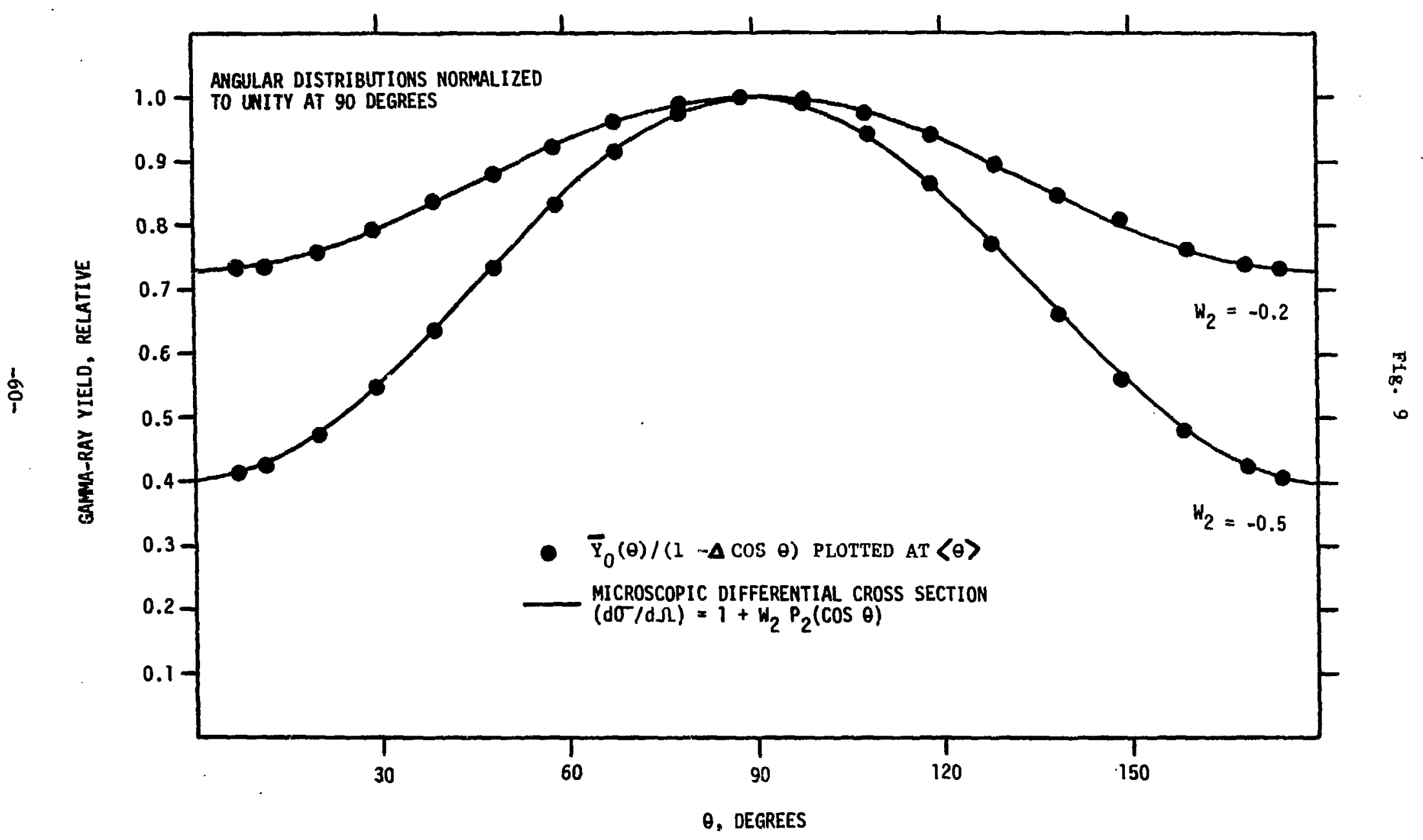


Fig. 10
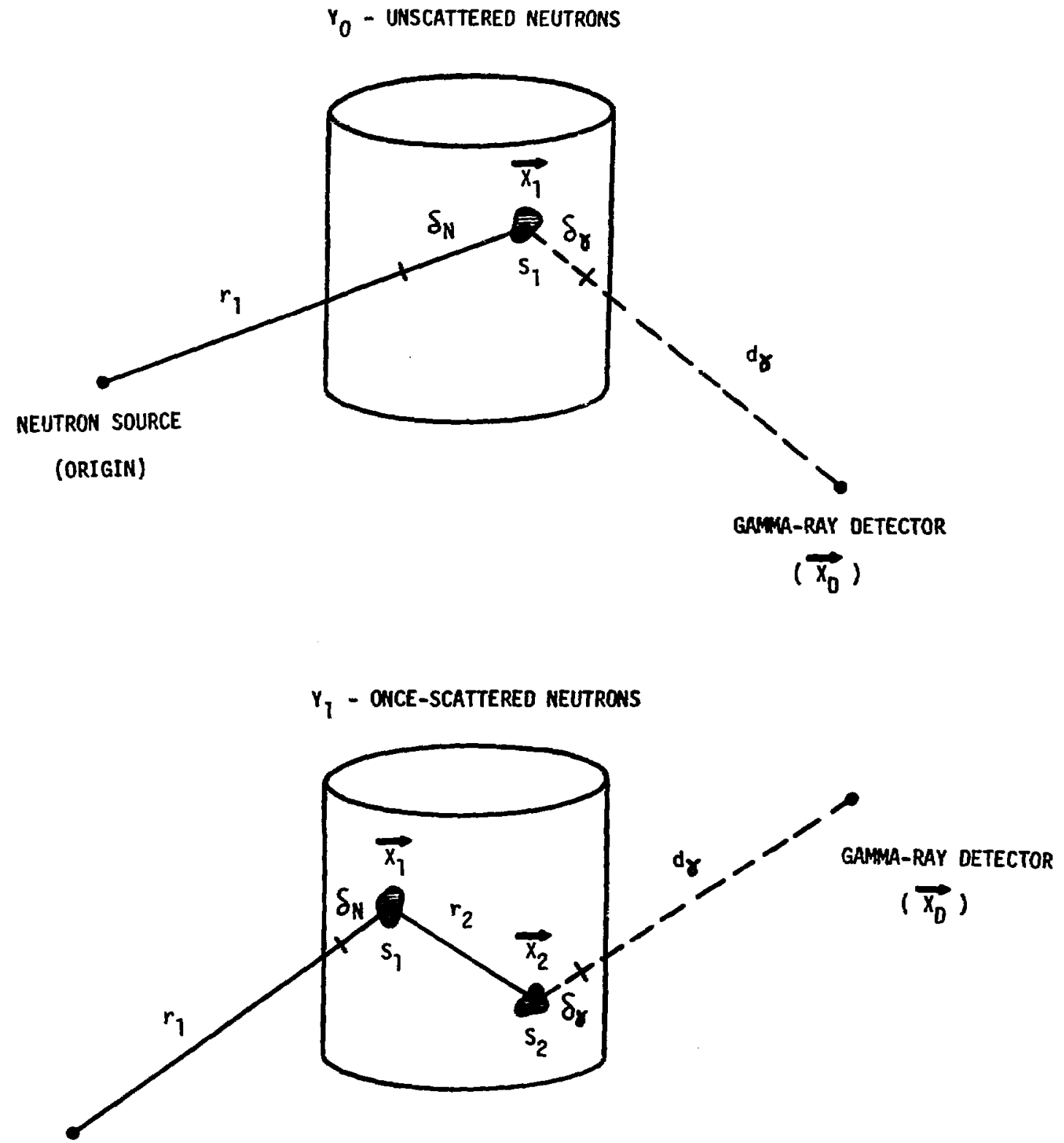

NEUTRON SOURCE

(ORIGIN) NEUTRON PATH

- - GAMMA-RAY PATH 
Fig. 11

- monte-carlo calculations

$-\left(1-\Delta \cos \theta_{\mathrm{DET}}\right)$ FITS

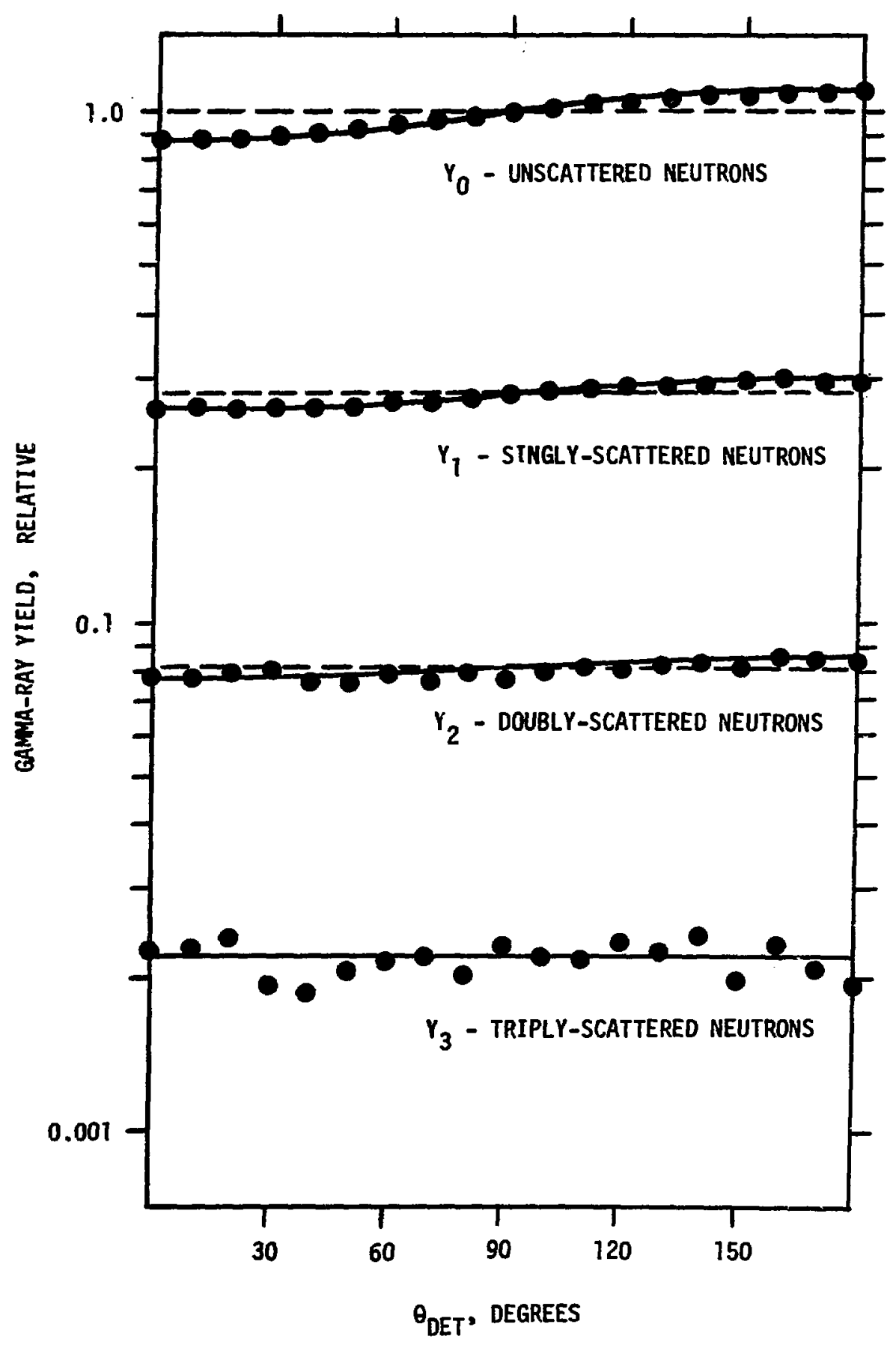




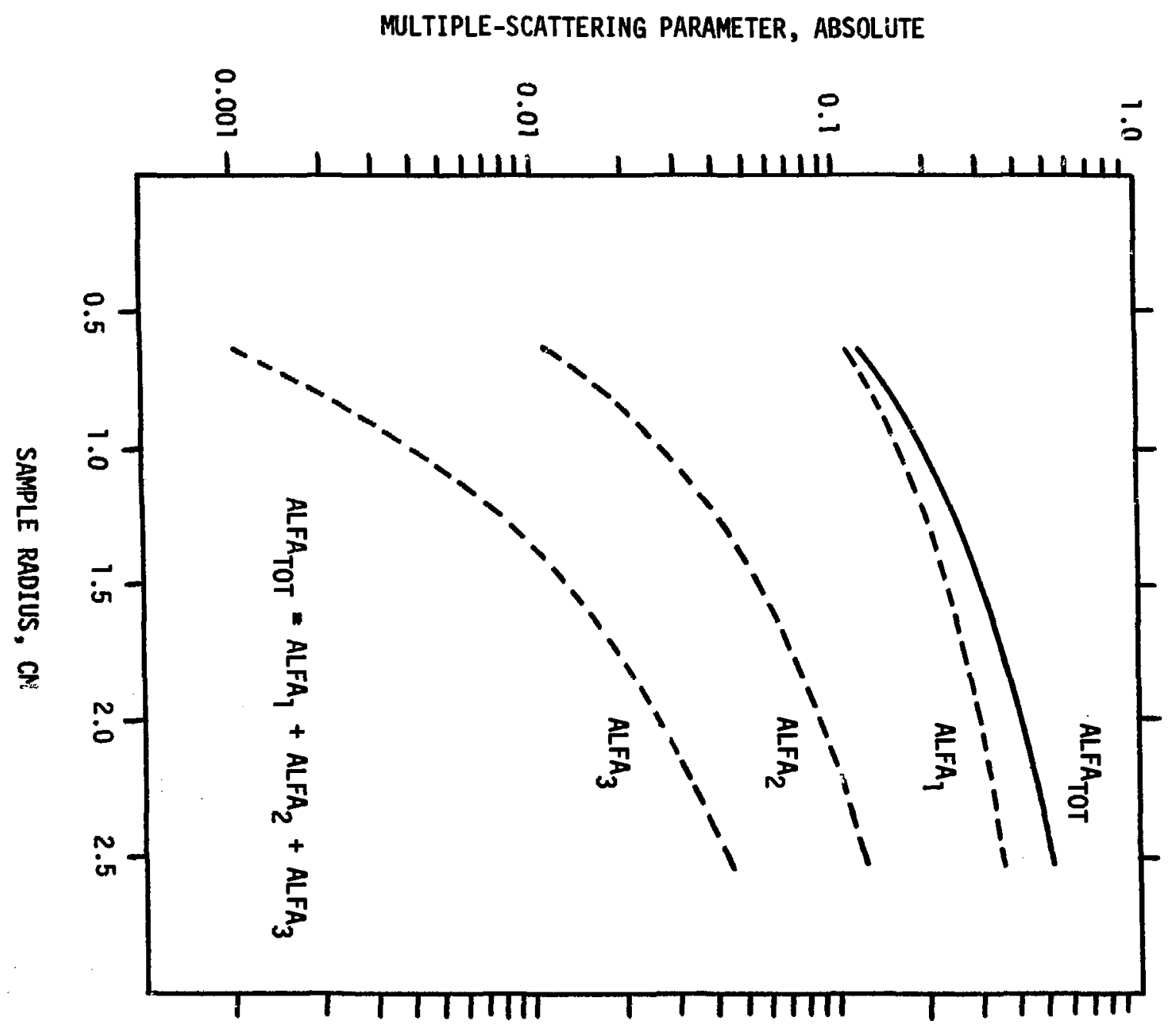


Fig. 13

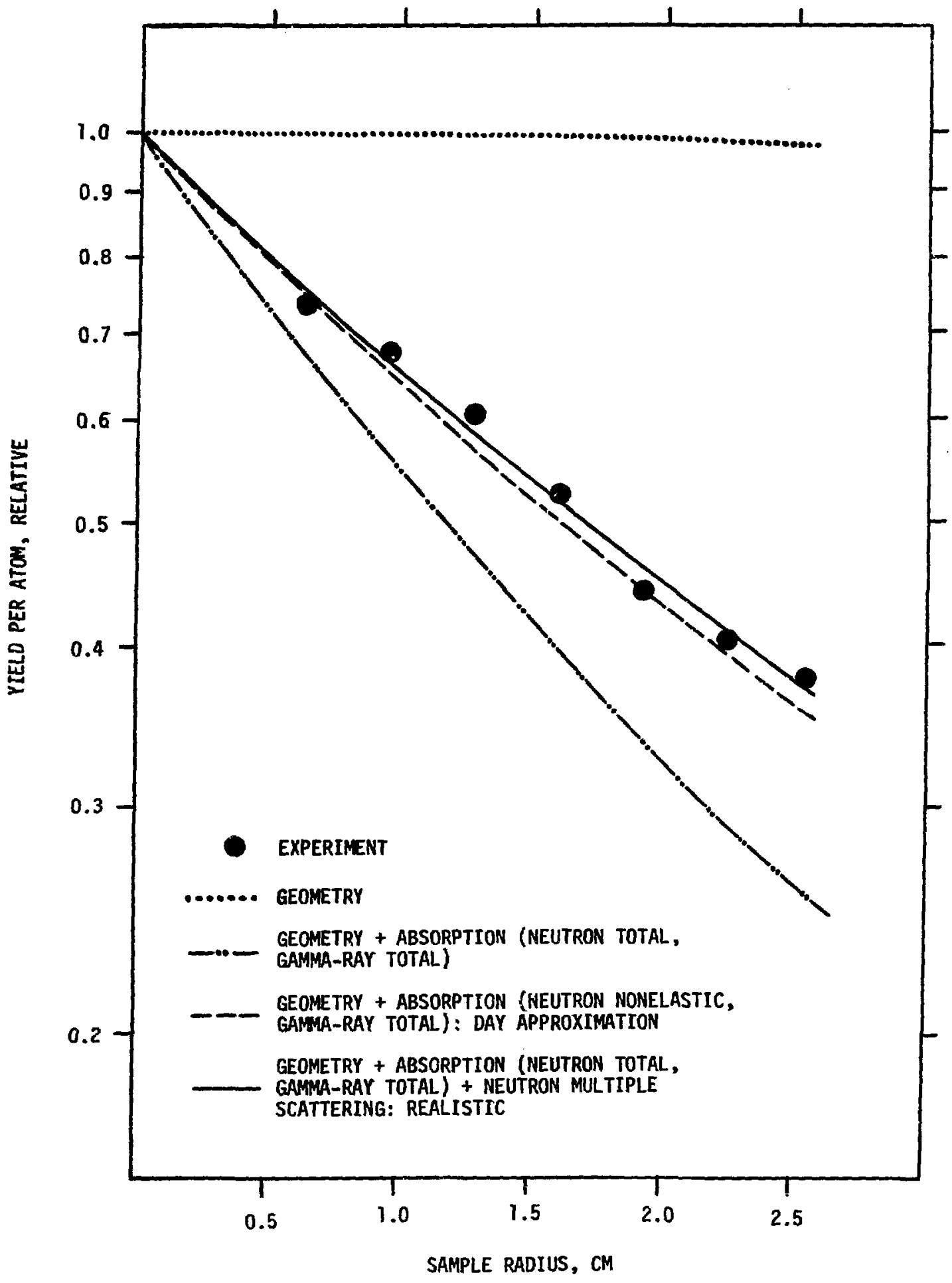

